\title{
Neural Network Analysis of the Influence of Processing on Strength and Ductility of Automotive Low Carbon Sheet steels
}

C. Capdevila, C. Garcia-Mateo, F. G. Caballero and C. García de Andrés.

MATERALIA Research Group Department of Physical Metallurgy, Centro Nacional de

Investigaciones Metalúrgicas (CENIM), CSIC, Avda Gregorio del Amo, 8, 28040, Madrid, Spain.

Contact author : Dr. Carlos García-Mateo

E-mail Address: cgm@cenim.csic.es

Phone: 34915538900 (ext. 364)

Fax: 34915347425

Mail Address : Centro Nacional de Investigaciones Metalúrgicas (CENIM), CSIC, Avda Gregorio del Amo, 8, 28040, Madrid, Spain.

\footnotetext{
Abstract

The goal of the work reported in this paper is to develop a neural network model for describing the evolution of mechanical properties such as yield strength (YS), ultimate tensile strength (UTS), and elongation (El) on low carbon sheet steels. The models presented here take into account the influence of 21 parameters describing chemical composition, and thermomechanical processes such as austenite and ferrite rolling, coiling, cold working and subsequent annealing involved on the production route of low carbon steels. The results presented in this paper demonstrate that these models can help on optimizing simultaneously both strength and ductility for the various types of forming operation that the sheets can be subjected to.
} 


\section{Keywords}

Neural network, strength, ductility, low carbon steels, processing parameters.

\section{Introduction}

Nowadays it exist a strong and accelerating trend towards the use of steels with higher and increasing strength levels. This is particularly true for applications in the automotive industry but a similar tendency is seen for all categories of materials user. Higher strength levels imply greater load bearing capacity and, therefore, the ability to obtain the same function in a product while using less material. For the customer this means that economies are possible since less material must be purchased. When used in vehicles, the lower weight, thanks to the use of high strength steel, improves fuel economy giving lower running costs and environmental benefits throughout their whole working life. The emphasis on safety and crash-worthiness in vehicles has also focussed the need for low carbon sheet steels having high strength. In general, whenever higher strength steel is substituted there is a reduction in the amount of steel that has to be produced and this means savings in energy during iron and steel making, smaller amounts of waste products and smaller emissions of $\mathrm{CO} 2$ into the atmosphere.

Mechanical properties of rolled sheet steel are main dependent on rolling scheme. The influence of rolling parameters on mechanical properties of low carbon sheet steels has been traditionally evaluated with the help of mathematical models, which unfortunately, supply neither a complete nor an exact description of the process. This makes continual recalculation of model parameters necessary, in order to adapt them to actual process 
events. A further drawback lies in the fact that the refinement potential for this process has been all but exhausted.

To overcome this shortcoming, it was decided to employ an entirely new tool, patterned to human brain: the 'neural network'. Such networks 'learn' from the massive volume of incoming data and the relationships involved and gain experience from systematic observation of recurring events.

This makes them capable of supporting traditional mathematical models or replacing them entirely. Their learning ability also enables neural networks to adapt continuously to change process states.

The goal of this paper is based upon the concepts described above. It aims to develop a neural network model for steel sheet products in order to optimize the processing parameter to deal with steels having a range of high strength levels in combination with adequate ductility for the various types of forming operation that the sheets can be subjected to. During cold rolling which is a necessary stage in production, the steel becomes intensely hardened but loses almost all its ductility. During conventional processing this strengthening is sacrificed to restore ductility. Then, if higher strength is demanded, it is achieved by either alloying or by special heat treatments at higher temperatures. The model proposed in this paper allows to predict processing parameters to retain as much of the strength from cold rolling as possible while at the same time restoring adequate ductility by controlled low temperature annealing.

\section{Build of the model}

\section{The experimental database}

The mechanical properties such as YS, UTS, and El in any model ideally require a complete description of the chemical composition and processing parameters. A 
literature survey [1-3] allows us to collect 590 individual cases where detailed chemical composition, hot-rolling and ferritic rolling processing parameters, cooling rate, coiling temperature, cold reduction and isothermal temperature values were reported. Table 1 shows the list of 20 input variables used for the YS, UTS and El properties analysis.

The variables considered here tend to cover most of the stage of hot rolling for sheet steels. Finishing rolling temperature (FRT), reduction in austenite (Red-A) and/or ferrite field (Red-F), cooling rate (CRate) down to coiling temperature (CT) are the parameters selected to describe the hot rolling process. Chemical composition, in particular carbon (C), manganese (Mn), silicon (Si), phosphor (P), sulphur (S), aluminium (Al) and nitrogen $(\mathrm{N})$ contents have been considered. Microalloying additions have been also considered in this study, in particular titanium (Ti), niobium (Nb) and vanadium (V) additions. Cold rolling process through the cold reduction (CR) has been considered. Finally, annealing stage has been included in the models developed through the following parameters: heating rate $(\mathrm{HR})$ from room temperature up to annealing temperature $(\mathrm{T})$, isothermal holding time $(\mathrm{t})$, and cooling rate down to room temperature (Cooling) have been considered as the most characteristic parameters of this stage.

\section{Brief description of neural network}

The aim is to be able to estimate the YS, UTS and El mechanical properties as a function of the variables listed in Table 1. In the present case, the network was trained using a randomly chosen of 296 examples from a total of 590 available; the remaining 294 examples were used as new experiments to test the trained network. Linear functions of the inputs $x_{j}$ are operated by a hyperbolic tangent transfer function

$$
h_{i}=\tanh \left(\sum_{j} w_{i j}^{(1)} x_{j}+\theta_{i}^{(1)}\right)
$$


So that each input contributes to every hidden unit. The bias is designated $\theta_{i}^{(l)}$ and is analogous to the constant that appears in linear regression. The strength of the transfer function is in each case determined by the weight $w_{i j}{ }^{(l)}$. The transfer to the output $y$ is linear

$y=\sum_{i} w_{i}^{(2)} h_{i}+\theta^{(2)}$

This specification of the network structure, together with the set of weights, is a complete description of the formula relating the inputs to the output. The weights were determined by training the network and the details are described by MacKay $[4,5]$. The training involves a minimization of the regularized sum of squared errors. The term $\sigma \mathrm{v}$ used below was the framework estimation of the noise level of the data.

Fig. 1 shows that the inferred noise level decreases monotonically as the number of hidden units increase. However, the complexity of the model also increases with the number of hidden units. To find out the optimum number of hidden units of the model the following procedure was used. The experimental data were partitioned equally and randomly into a test dataset and a training dataset. Only the latter was used to train the model, whose ability to generalist was examined by checking its performance on the unseen test data. The test error (Ten) is a reflection of the ability of the model to predict in the test data:

$$
T_{e n}=0.5 \sum_{n}\left(y_{n}-t_{n}\right)^{2}
$$

where $y_{n}$ is the set of predictions made by the model and $t_{n}$ is the set of target (experimental) values.

A high degree of complexity may not be justified, and in an extreme case, the model may in a meaningless way attempt to fit the noise in the experimental data. MacKay $[6,7]$ has made a detailed study of this problem and defined a quantity (the 'evidence') 
which comments on the probability of a model. In circumstances where two models give similar results for the known data, the more probable model would be predicted to be that which is simpler; this simple model would have a higher value of evidence. The evidence framework was used to control $\sigma_{v}$. The number of hidden units was set by examining performance on test data. A combination of Bayesian and pragmatic statistical techniques were therefore used to control the complexity of the model. [6-8]. Fig. 1 also shows that a large number of hidden units did not give significantly lower values of $\sigma_{v}$; indeed, eleven hidden units were found to give a reasonable level of complexity to represent the variations of YS and UTS as a function of the input variables of Table 1, meanwhile only five hidden units were enough for El model.

On the other hand, it is possible that a committee of models can make a more reliable prediction than an individual model. The best models were ranked using the values of their test errors (equation (3)) as Fig. 2(a) to Fig. 2(c) present, for the respective YS, UTS, and El properties. Committee of models could then be formed by combining the pred iction of the best $L$ models, where $\mathrm{L}=1,2, \ldots$ The size of the committee is therefore given by the value of $L$.

The combined test error of the predictions made by a committee of $L$ models, ranked 1 , $2 \ldots q \ldots L$, each with $n$ lines of test data, is calculated in a similar manner to the test error of a single model:

$$
\begin{aligned}
& T_{e n}=0.5 \sum_{n}\left(\overline{y_{n}}-t_{n}\right)^{2} \\
& \bar{y}_{n}=\frac{1}{L} \sum_{q} y_{n}^{(q)}
\end{aligned}
$$

where $y_{n}^{(q)}$ is the set of predictions made by the model and $t_{n}$ is the set of target (experimental) values. 
As Fig. 2 suggests the combined test error goes through a minimum for the committee made up of four models for YS model, two models for UTS model, and six models for EL model.

From a comparison between results presented in Fig. 2 it is clear a reduction in test error and hence improved predictions by using the committee of models approach instead of the best model alone. Comparison between the predicted and measured values of YS, UTS and EL for the training and test data is shown in Fig. 3 for the best committee of each YS, UTS, and EL.

However, the practice of using a best-fit function does not adequately describe the uncertainties in regions of the input space where data are spare or noisy. MacKay [6,7] has developed a particularly useful treatment of neural networks in a Bayesian framework, which allows the calculation of error bars representing the uncertainty in the fitting parameters. The method recognizes that there are many functions which can be fitted or extrapolated into uncertain regions of the input space, without unduly compromising the fit in adjacent regions which are rich in accurate data. Instead of calculating a unique set of weights, a probability distribution of sets of weights is used to define the fitting uncertainty. The error bars therefore become larger when data are spare or locally noisy.

Fig. 4 illustrate the significance $\left(\sigma_{w}\right)$ of each of the input variables, as perceived by the neural network, in influencing the YS, UTS and EL mechanical properties. The variables analysed are organized in three groups, i.e. hot rolling, chemical composition and cold rolling and annealing. The value of $\sigma_{w}$ is normalized to 100 , i.e. the value of $\sigma_{w}$ for a specific variable indicates the degree of influence in percentage. The metallurgical significance of the results predicted by the models is discussed below, but a first approximation of the influence of each one of the variables studied could be drawn from a close observation of Fig. 4. 
As general comment for the three models developed, it is clear that the annealing temperature (T) after cold rolling, together with holding time at such temperature $(\mathrm{t})$, clearly have a large intrinsic effect on mechanical properties, which is consistent with experimental evidences reported in the literature since decades. In terms of hot rolling processing parameters the finishing rolling temperature (FRT) has a relative low influence in the three modelled properties, on the other hand the relevance of reduction in austenite (Red-A) or ferrite region (Red-F) changes depending on the model, thus for the YS the relevance is relatively low while in the UTS and EL is higher. It is also clearly evident that the influence of cooling rate (CRate) after hot rolling down to coiling temperature is almost negligible for all the three models created.

It is surprising the small effect that coiling temperature (CT) has on the three models developed. This is because of the small actual range of temperatures studied. Although the hypothetical range of $\mathrm{CT}$ values is from 20 to $750{ }^{\circ} \mathrm{C}$ (see Table 1), the average value is $654{ }^{\circ} \mathrm{C}$ which indicate that most of the data fall in the range of $600-700{ }^{\circ} \mathrm{C}$. This can explain why the models are not very sensitive to CT. More data covering additional $\mathrm{CT}$ are required.

Regarding the influence of chemical composition, it is clear that carbon content (C) significantly affect the YS, UTS, and particularly EL. Manganese (Mn) and phosphor (P) contents exhibit an increasing influence on YS, UTS and El respectively. Microalloying element such as $\mathrm{Ti}$ and $\mathrm{Nb}$ have a significant influence on YS, by contrast such elements have a moderate or little influence on UTS and EL models.

\section{Results and discussion}

Influence of carbon content

It is well known the role of carbon strengthening the steels, and hence decreasing ductility. In this work, a base steel with composition and processing parameters shown in the first column of Table 2 but carbon ranging from 0.001 to 0.1 has been considered 
for calculations. Fig. 5 shows the effect of carbon content on YS, UTS and EL mechan ical properties. It is clear from this Fig. that meanwhile ultimate tensile strength and yield strength increase, elongation consequently decreases as carbon content increases. This is an expected behaviour, which indicates that the model can predict reasonable results. However, it is worth mentioning that the hardening of the material, i.e. the difference between YS and UTS value increases as carbon content increases as it is shown in Fig. 5(a).

Influence of cooling rate

Cooling rate after annealing has a reasonable influence on YS, UTS and EL models according to Fig. 6. Steel tested for calculations is listed in the second column of Table 2. Likewise, it has been observed [9] that recrystallisation has not finished completely during the short annealing of $10 \mathrm{~s}$ at $700{ }^{\circ} \mathrm{C}$ in the steel listed in Table 2 for Fig. 6. Therefore, as faster the cooling rate after annealing is, the finer the microstructure is, which should lead to the strengthening of the material. On the other hand, dissolution of cementite is produced during heating and holding at $700{ }^{\circ} \mathrm{C}$ in the annealing processes. If cooling rate is slow enough, carbon will precipitate during subsequent cooling contributing to the strengthening of the material. Moreover, this precipitation could be avoided for fast cooling after annealing, producing a strengthening for solid solution of carbon of the microstructure.

In this sense, Fig. 6 shows the evolution of YS, UTS and El with cooling rate after annealing. It is clear that as cooling rate increases, YS and UTS increases meanwhile El decreases, which is consistent with the above idea that increase cooling leads to a strengthening of the material. However, the huge error bars for fast cooling rates, which indicate a lack of data in the dataset for these cooling rates, does not allow to extract 
reliable data from the models, although the trend of data is correct. Further increase of data in this range is required.

Influence of Annealing Temperature

In order to analyse the effect of annealing temperature after cold rolling, the steel listed in the third column of Table 2 has been selected, i.e. an extra low carbon steel with $\mathrm{CR}=75 \%$. Fig. 7 shows the influence of annealing temperature on UTS and EL mechan ical properties maintaining a constant isothermal holding time of $10 \mathrm{~s}$. It is clear that this temperature affects enormously the evolution of such mechanical properties. This is a consequence of static recrystall is ation process [10], which leads to an increase of ductility in detriment of strength (Fig. 8).

There is a great interest in optimizing, both at the same time, strength and ductility for low carbon sheet steels. The aim is to develop steel sheet products having a range of high strength levels in combination with adequate ductility for the various types of forming operation that the sheets can be subjected to. During cold rolling, which is a necessary stage in production, the steel becomes intensely hardened but loses almost all its ductility. During conventional processing this strengthening is sacrificed to restore ductility by a conventional annealing. Then, if higher strength is demanded, it is achieved by either alloying or by special heat treatments at higher temperatures. The model presented here was built with the intention of indicate the parameters at which it could be possible to retain as much of the strength from cold rolling as possible while at the same time restoring adequate ductility by controlled low temperature annealing. This goal is achieved from analyzing data such as those in Fig. 7. It is clear that the best compromise between strength level and a reasonable level of ductility is achieved after annealing $10 \mathrm{~s}$ at $625^{\circ} \mathrm{C}$ (see cross point in Fig. 7). 
Fig. 9 shows the comparative evolution of UTS and YS with annealing temperature. It is clear that as annealing temperature increases, the difference between UTS and YS is increased.

On the other hand, Fig. 10 shows the combined effect of carbon content and annealing temperature on UTS and El on the same steel than that used for calculations on Fig. 5 and 7 (see Table 2). This Fig. shows that surprisingly there is a significant, and simultaneous, increase on UTS and El as carbon content and annealing temperature increases. Bearing in mind that as carbon content increases the temperature at which austenite is formed decreases, this apparently strange result could indicate a microstructural effect. Higher annealing temperature in a 0.015 wt.- $\%$ carbon steels leads to a mixture of ferrite and austenite microstructure. Such microstructure will transform into a ferrite martensite microstructure during subsequent cooling. This dual microstructure has a higher UTS and EL values than a ferritic one.

\section{Applications}

Case study: Role of Ti and Nb on high strength ULC steels

An appropriate texture is the key factor for good forming properties in ULC steels [11]. It has been reported that AlN precipitation during recrystallisation impedes the selective nucleation of preferred orientations, and grain growth, leading to an unfavourable texture for drawing together with a strengthening by grain refinement. Moreover, the presence of carbon in solid solution during recrystallisation further enhances the unfavourable texture. Consequently, to obtain a good drawability with annealing after cold - rolling, it is necessary to reduce the concentrations of interstitial elements (carbon and nitrogen) in solid solution [10]. In this sense, the carbon and nitrogen are completely tied up as precipitates, due to controlled addition of one or more strong carbide or nitride forming elements, such as titanium and niobium. 
The YS/ULC ratio could be used as an index for the goodness of drawing properties. In this sense, Fig. 11 and 12 show the evolution of YS/UTS and EL with microalloying elements content. The steels used for calculation are listed in Table 3. The concentration in this graph has been considered as the ratio between the $\mathrm{X}$-element concentration ([X]), i.e. concentration of $\mathrm{Ti}$ or $\mathrm{Nb}$, and the maximum concentration of $\mathrm{Ti}$ or $\mathrm{Nb}$ considered $\left([X]_{\max }\right)$, i.e. $[X] /[X]_{\max }$. It is clear that the higher the Ti content are, the lower the YS/UTS ratio is, which indicate that Ti additions are beneficial from the improvement of formability properties point of view. However, the YS/UTS ratio increases as $\mathrm{Nb}$ additions increase, which is detrimental for formability properties.

The behaviour presented in Fig. 11 could be related with precipitation sequences of the Ti- and Nb-rich steels. Ti(C,N) are very effective either delaying recrystallisation of austenite after hot rolling and either pinning the growth of recrystallise austenite grains [12]. Such refinement of the austenite microstructure leads to a finer ferrite microstructure, which is the characteristic microstructure for steel with chemical composition listed in Table 2.

Case study 2: Control of coiling temperature on ELC steels

The presence of carbides and carbon in solid solution during recrystallisation further enhances the unfavourable texture for drawing applications in ELC steels. Consequently, an annealed product is endeavoured to promote recrystallisation in a ferritic matrix from which the nitrogen has been precipitated as AIN before annealing, and whose dissolved carbon content and cementite volume fraction are low. In the case of nitrogen, precipitation of AlN is obtained by high temperature coiling or by reheating the slab at temperatures to low to take the nitrides back into solution, Control of dissolved carbon and carbide contents is achieved by lowering the carbon level of the 
steel, and to coarsen the cementite particles to limit their number and decrease the rate of re-dissolution during annealing. High temperature coiling also promotes such coarsening. Thus, an increase of coiling temperature may improve the formability properties, due to precipitation of AIN and coarsening of cementite. Assuming the ratio YS/UTS as an indicator of formability, this assumption is fully consistent with the results presented in Fig. 12 where YS/UTS ratio is analysed in the steel listed in the fifth column of Table 2 as a function of coiling temperature and carbon content.

\section{Conclusions}

It has been developed three neural network models, under a Bayesian framework, to study the variation of YS, UTS, and El with 21 parameters including chemical composition, and processes such as austenite rolling, ferritic rolling, coiling, cold working and subsequent annealing on automotive low carbon steels.

The annealing temperature after cold rolling, together with holding time at such temperature, clearly has a large intrinsic effect. Processing parameters of hot rolling such as finishing rolling temperature (FRT) has a relative low influence on the models, reduction in austenite (Red-A) and ferrite region (Red-F) have different relevance on the models, thus in YS is very low but it is higher in UTS and El.

Carbon content significantly affects the YS, UTS, and specially El mechanical properties. Mn and P contents have a significant influence of UTS and El, but not in YS model. In the latter, microalloying element such as $\mathrm{Ti}$ and $\mathrm{Nb}$ have a significant influence on YS. By contrast such elements have a very little influence on UTS and EL mechan ical property models.

Models presented in this paper predict an strengthening of the steel for increasing amounts of carbon and faster cooling rates after annealing, which is fully consistent with experimental results reported on literature. 
The models developed in this work could be successively employed on calculating the annealing conditions which ensure the better combination of high strength levels with adequate ductility for the various types of forming operation that the sheets can be subjected to.

It has been shown the utility of the neural network models developed to optimise the microalloying additions in order to improve the YS/UTS ratio which it is considered as the best indication of good drawability properties of ULC steels.

The model has been applied successfully to analyse the combined effect of coiling temperature and carbon content on the improvement of YS/UTS ratio in ELC steels.

\section{Acknowledgements}

The authors acknowledge financial support from European Community and Spanish Ministerio de Educación y Ciencia in the form of ECSC Project (ECSC 7210-PR-368) and a Complementary Project (MAT 2002-10810E). Authrs acknowledge T. Iung (France) from Arcelor Reserch, J. Spearl from Voest Alpine Stahl (Austria), M. Bartieri from Centro Sviluppo di Materiali (Italy), and Bevis Hutchinson from KIMAB (Sweden) for the fruitful discussions. C. García-Mateo would like to thank the Spanish Ministerio de Ciencia y Tecnología for the financial support in the form of a Ramon y Cajal contract. The authors also are grateful to Neuromat Ltd. for the provision of the neural network software used in this work.

\section{References}

[1] A. Pichler, H. Spindler, C. Van Durme, P.E. Di Nunzio, K. Spiradek, W. Bleck and S. Greisler, 'Precipitation behaviour in the ferrite range of soft microalloyed ULC steel grades', Final Report, ECSC 7210-EC/119, EU, Brussels, 2000. 
[2] W. Bleck, C. Van Dume, S.D. Daniel, W.B. Hutchinson, H.J. Grabke, G.N. Ha idemenopoulos, P. Stiaszny, 'New Cold-rooled deep-drawing qualities', ECSC 7210EC/115, EU, Brussels, 1999.

[3] P.J. Evans, I. Gutieerez, M.M. Petite, J.I. Larburu, J. Zaitegui, W.B. Hutchinson, D. Artymowicz, G.J. Spurr, H.K.D.H. Bhadeshia, N. Chester, 'Modelling of microstructural development during continuous annealing process', ECSC 7210EU/808, EU, Brussels, 1998.

[4] D.J.C. MaKay: Neural Comput., 4 (1992) 698-705.

[5] D.J.C. MaKay: Darwin college J., March (1993) 81-93.

[6] D.J.C. MaKay: Neural Comput., 4 (1992) 415-422.

[7] D.J.C. MaKay: Neural Comput., 4 (1992) 448-460.

[8] H.K.D.H. Bhadeshia: ISIJ Int., 39 (1999) 965-979.

[9] C. Capdevila, T. De Cock, F.G. Caballero, C. García-Mateo and C. García de Andrés, Materials Science Forum, 467-470 (2004) 863-868.

[10] C. Capdevila, T. De Cock, C. García-Mateo, F. G. Caballero, and C. García de Andrés, Materials Science Forum, 500-501 (2005) 803-810.

[11] W.B. Hutchinson, Int. Metals Reviews, 29 (1984) 25-42.

[12] David San Martín, F.G. Caballero, C. Capdevila and C. García de Andrés, Materials Transactions JIM, 45 (2004) 2797-2804.

\section{Figures captions}

Fig. 1. Variation of inferred noise level $\left(\sigma_{V}\right)$ as a function of the number of hidden units for (a) YS, (b) UTS, and (c) El models.

Fig. 2. Test error values of the twenty best models, and the committee, for (a) YS, (b) UTS, and (c) EL models. 
Fig. 3. Comparison between the predicted and measured values of (a) YS, (b) UTS, and (c) EL using their respective committee of models.

Fig. 4. Histogram showing the significance of input variables in influencing (a) YS, (b) UTS, and (c) EL mechanical properties perceived by their respective models.

Fig. 5. Influence of carbon content on (a) YS, UTS and (b) EL mechanical properties.

Fig. 6. Evolution of (a) UTS and YS, and (b) El with cooling rate after annealing.

Fig. 7. Evolution of UTS and EL with annealing temperature (isothermal holding time of $10 \mathrm{~s})$.

Fig. 8. Comparison between UTS and recrytallisation volume fraction with annealing temperature. Recrystallisation volume fraction according to Ref. [10].

Fig. 9. Comparison between UTS and YS evolution with annealing temperature.

Fig. 10. Evolution of (a) UTS and (b) El with annealing temperature and carbon content.

Fig. 11. Influence of Ti and $\mathrm{Nb}$ on YS/UTS ratio.

Fig. 12. Evolution of YS/UTS as a function of coiling temperature and carbon content. 


\section{Tables}

Table 1. Variables that influence YS, UTS and EL mechanical properties. SD is standard deviation

\begin{tabular}{ccccc}
\hline & Minimum & Maximum & Average & SD \\
\hline FRT, ${ }^{\circ} \mathrm{C}$ & 400 & 930 & 916.9435 & 47.7139 \\
Red-A, $\%$ & 0 & 87 & 83.1558 & 11.0752 \\
Red-F, $\%$ & 0 & 92 & 1.5753 & 11.9455 \\
CRate, ${ }^{\circ} \mathrm{C} / \mathrm{s}$ & 10 & 400 & 31.3545 & 71.3761 \\
CT, ${ }^{\circ} \mathrm{C}$ & 20 & 750 & 654.1113 & 100.2767 \\
C,wt.- $\%$ & 0.002 & 0.08 & 0.0269 & 0.0247 \\
Mn,wt.-\% & 0.034 & 1.254 & 0.3136 & 0.1533 \\
Si,wt.- $\%$ & 0.001 & 0.283 & 0.007 & 0.0202 \\
P,wt.- $\%$ & 0.001 & 0.073 & 0.033 & 0.0295 \\
S,wt.- $\%$ & 0.001 & 0.022 & 0.0098 & 0.0053 \\
Al,wt.- $\%$ & 0.001 & 0.159 & 0.0413 & 0.0108 \\
N,wt.- $\%$ & 0.001 & 0.005 & 0.0037 & 0.001 \\
Ti,wt.- $\%$ & 0 & 0.083 & 0.0135 & 0.0138 \\
V,wt.- $\%$ & 0 & 0.003 & 0.0001 & 0.0005 \\
Nb,wt.- $\%$ & 0 & 0.022 & 0.0094 & 0.0067 \\
CR, $\%$ & 0 & 90 & 70.851 & 10.024 \\
HR, ${ }^{\circ} \mathrm{C} / \mathrm{S}$ & 4 & 3000 & 490.2877 & 873.822 \\
T, ${ }^{\circ} \mathrm{C}$ & 546 & 1112 & 772.298 & 94.3922 \\
t,s & 0 & 89 & 16.9065 & 24.0136 \\
Cooling, ${ }^{o} \mathrm{C} / \mathrm{s}$ & 10 & 500 & 311.3185 & 226.3589 \\
\hline EL, $\%$ & 1 & 53 & 28.786 & 13.685 \\
\hline YS, MPa & 104 & 740 & 313.407501 & 148.437698 \\
\hline UTS, MPa & 250 & 750 & 425.525696 & 125.164902 \\
\hline & & & &
\end{tabular}


Table 2. Parameters used for calculations.

\begin{tabular}{cccccc}
\hline & Fig. 5 & Fig. 6 & Fig. 7 & Fig. 11 \& 12 & Fig. 13 \\
\hline FRT, ${ }^{\circ} \mathrm{C}$ & 900 & 900 & 900 & 900 & 900 \\
Red-A, $\%$ & 85 & 85 & 85 & 85 & 85 \\
Red-F, $\%$ & 0 & 0 & 0 & 0 & 0 \\
CRate, ${ }^{\circ} \mathrm{C} / \mathrm{s}$ & 10 & 10 & 10 & 10 & 10 \\
CT, ${ }^{\circ} \mathrm{C}$ & 700 & 700 & 700 & 750 & Variable \\
C,wt.- $\%$ & variable & 0.014 & 0.015 & 0.003 & Variable \\
Mn,wt.-\% & 0.8 & 0.2 & 0.2 & 0.2 & 0.2 \\
Si,wt.- $\%$ & 0.04 & 0.02 & 0.02 & 0.02 & 0.02 \\
P,wt.-\% & 0.001 & 0.001 & 0.001 & 0.001 & 0.001 \\
S,wt.-\% & 0.003 & 0.001 & 0.001 & 0.001 & 0.001 \\
Al,wt.- $\%$ & 0.04 & 0.04 & 0.04 & 0.04 & 0.04 \\
N,wt.- $\%$ & 0.0023 & 0.003 & 0.003 & 0.003 & 0.003 \\
Ti,wt.- $\%$ & 0 & 0 & 0 & Variable & 0 \\
V,wt.- $\%$ & 0 & 0 & 0 & 0 & 0 \\
Nb,wt.- $\%$ & 0 & 0 & 0 & Variable & 0 \\
CR, $\%$ & 70 & 75 & 75 & 70 & 70 \\
HR, ${ }^{\circ} \mathrm{C} / \mathrm{S}$ & 10 & 10 & 10 & 10 & 10 \\
T, ${ }^{\circ} \mathrm{C}$ & 600 & 700 & Variable & 740 & 700 \\
t,s & 10 & 10 & 10 & 10 & 10 \\
Cooling, ${ }^{\circ} \mathrm{C} / \mathrm{s}$ & 10 & Variable & 10 & 10 & 10
\end{tabular}


Fig1a
Click here to download high resolution image

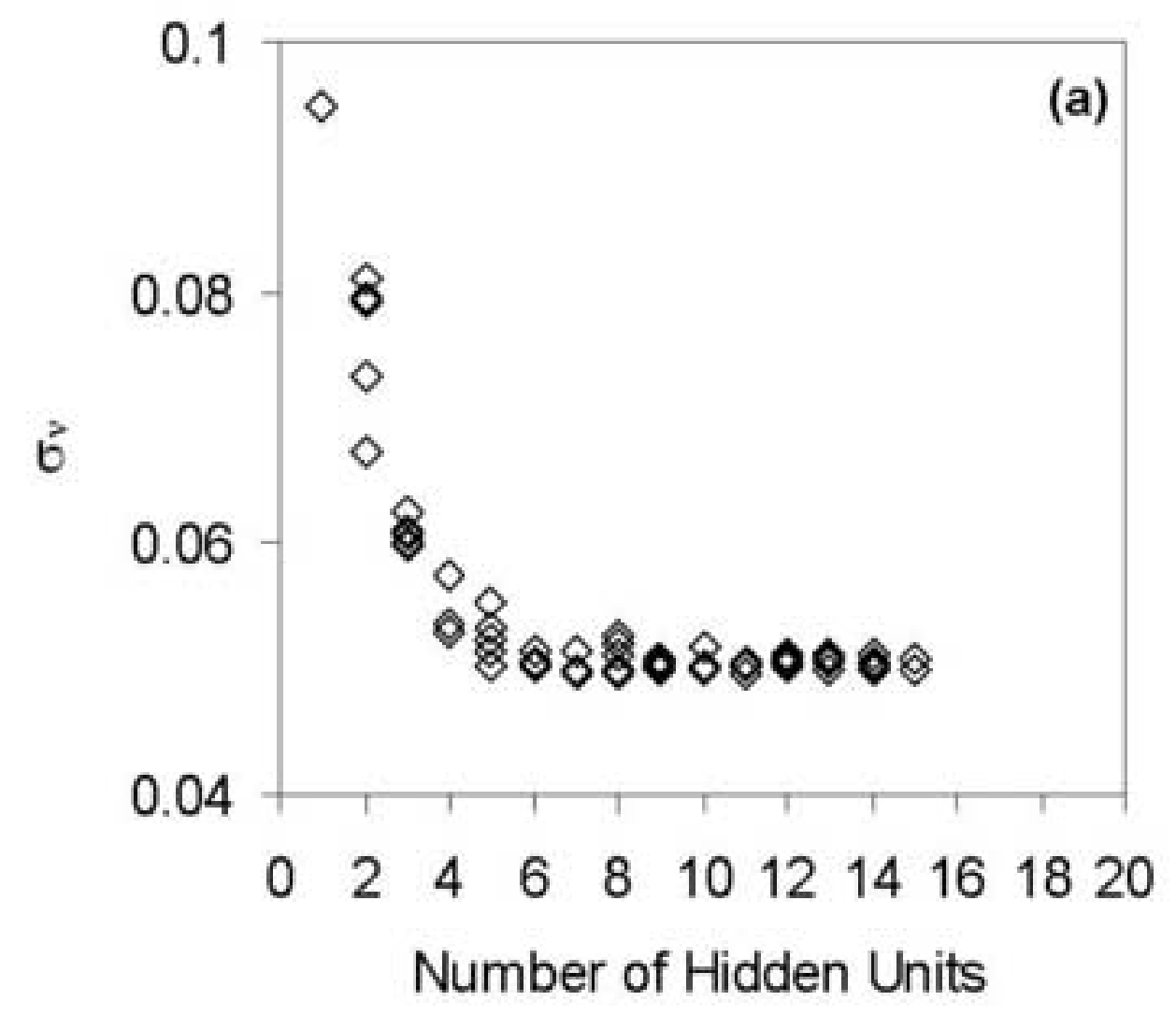


Flick here to download high resolution image

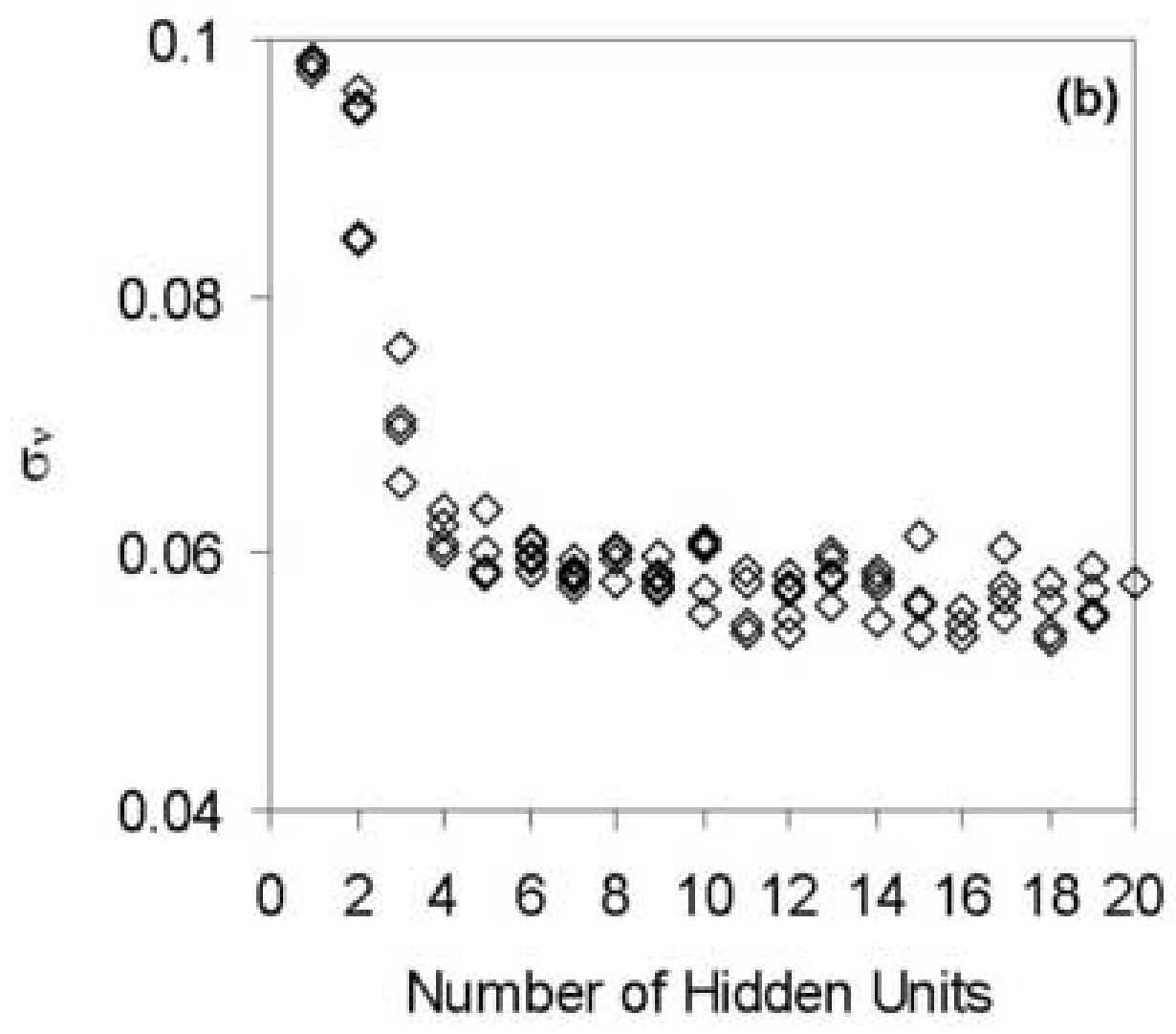


Fig1c
Click here to download high resolution image

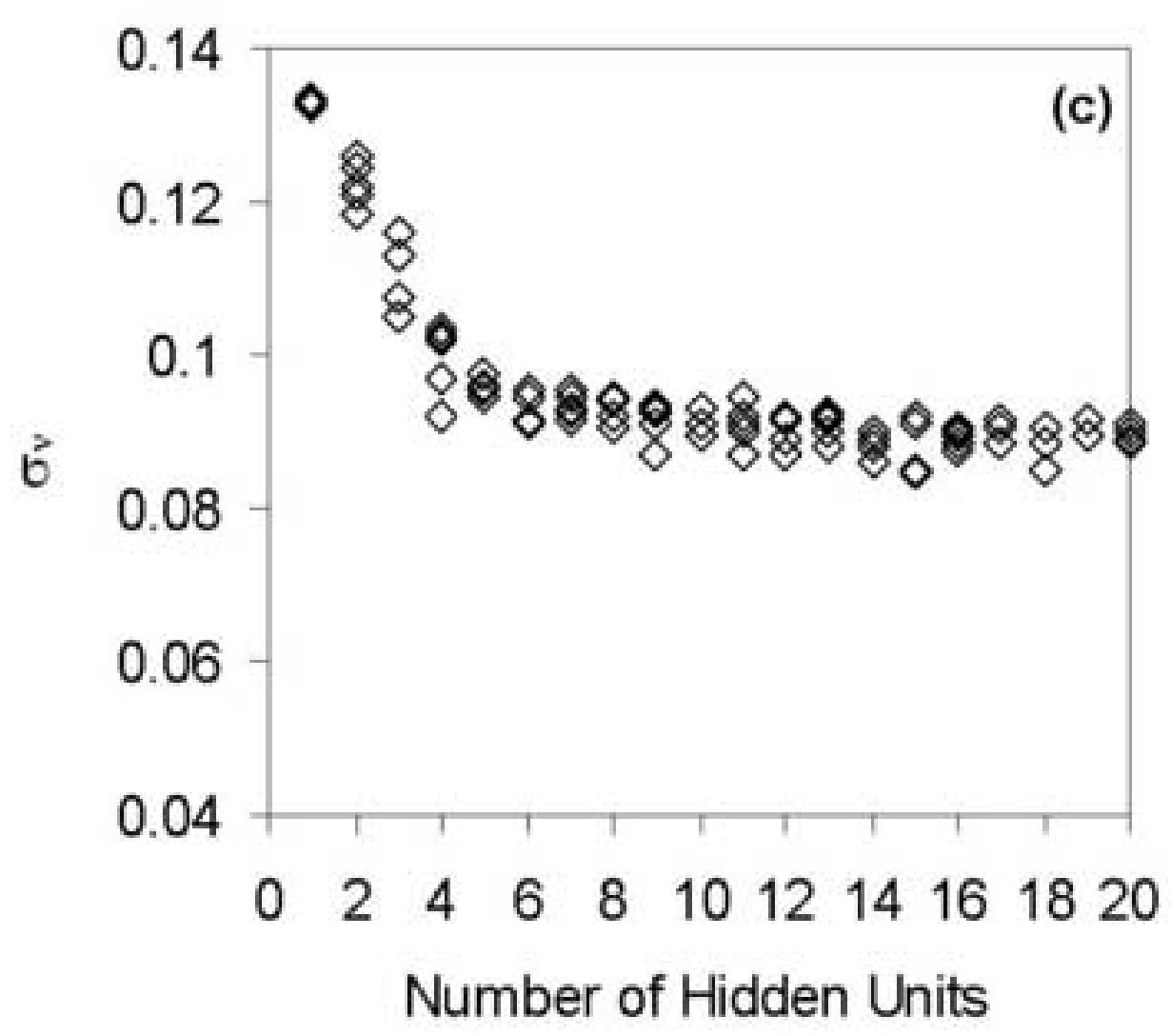


Click here to download high resolution image
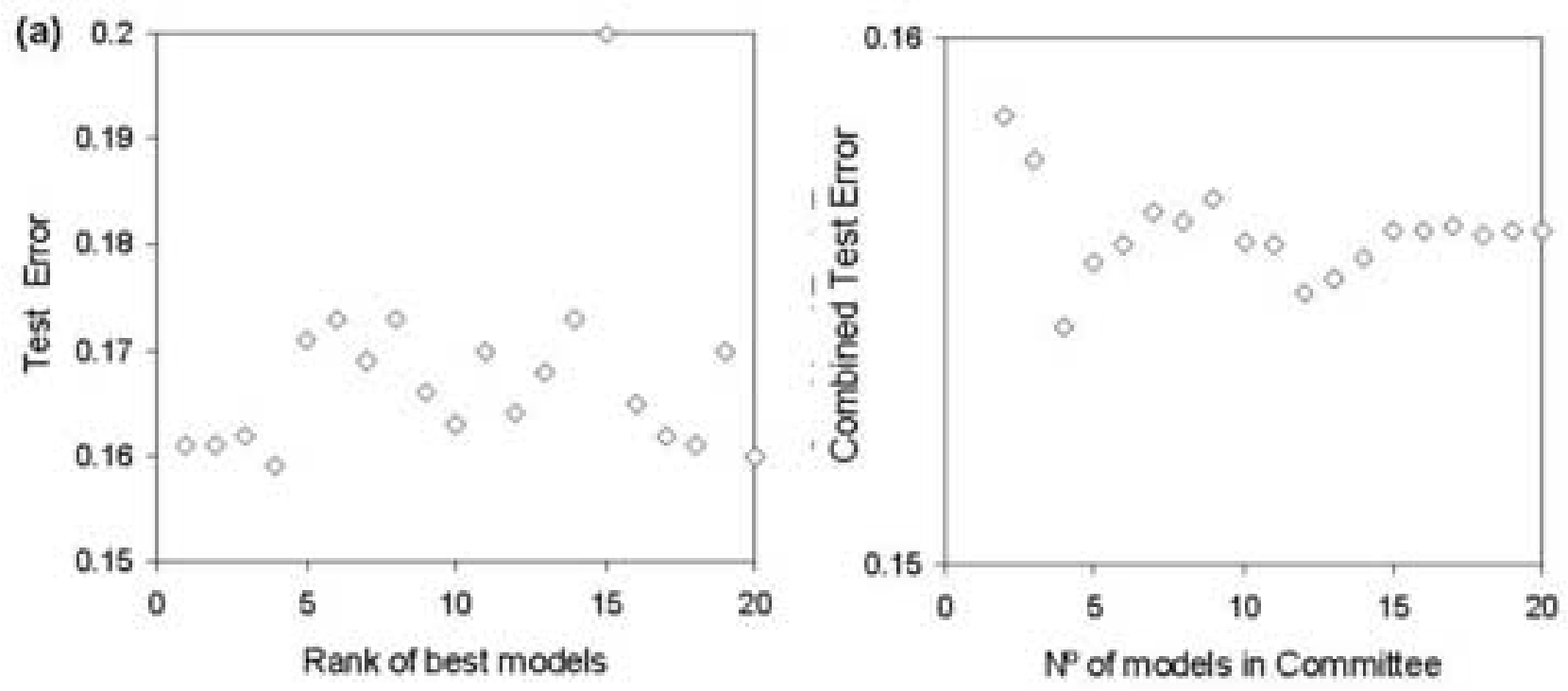
Fig2b
Click here to download high resolution image
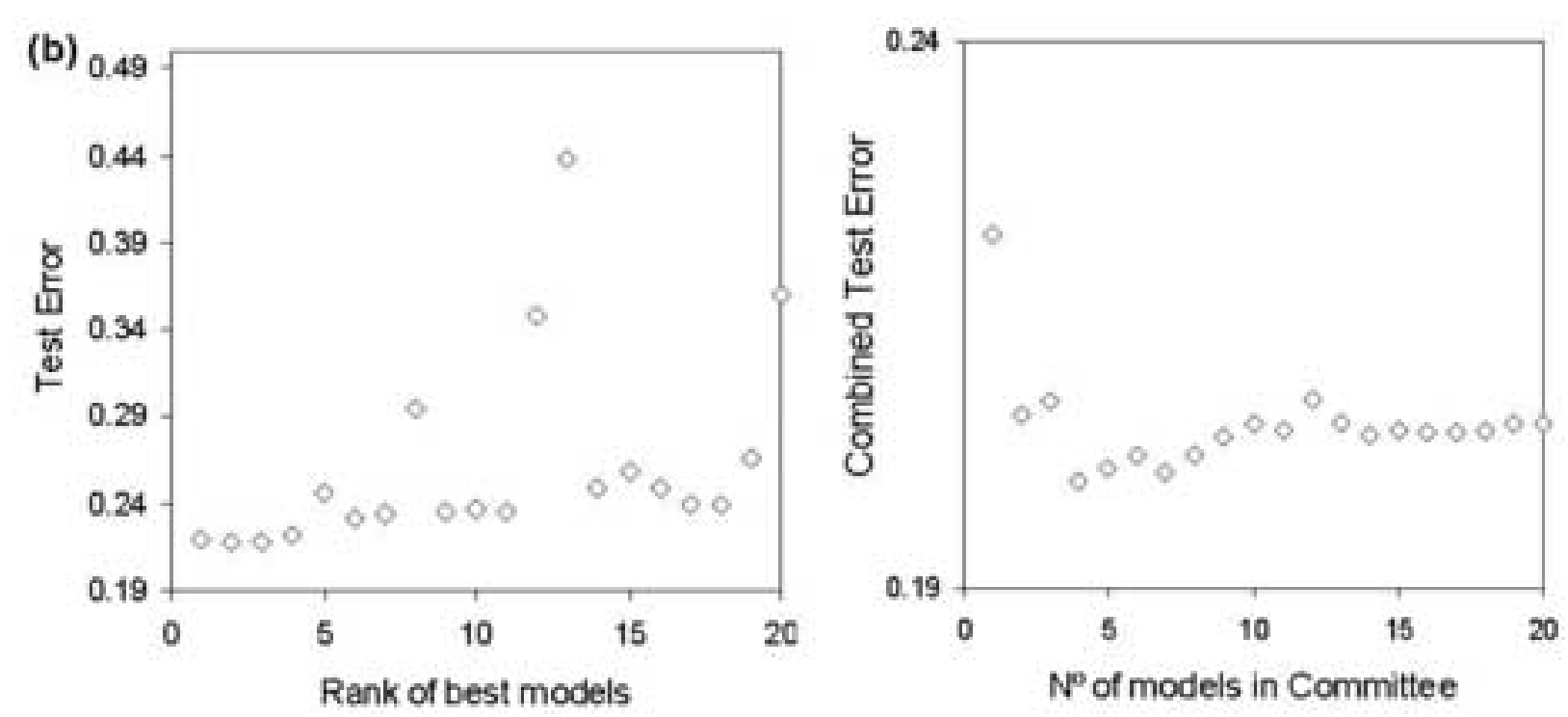
Fig2c
Click here to download high resolution image
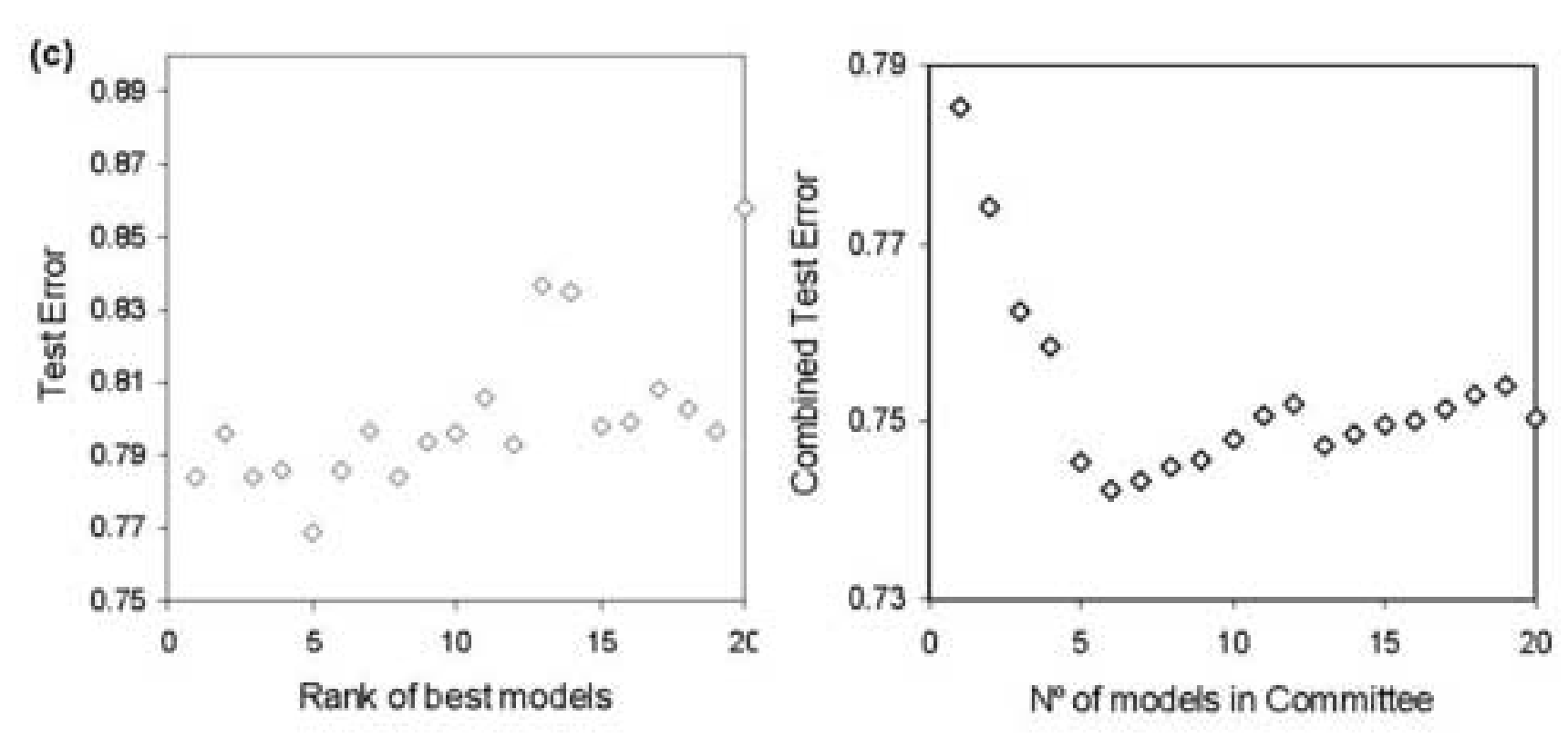

Rark of best models

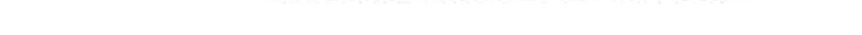

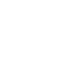

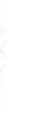


Click here to download high resolution image

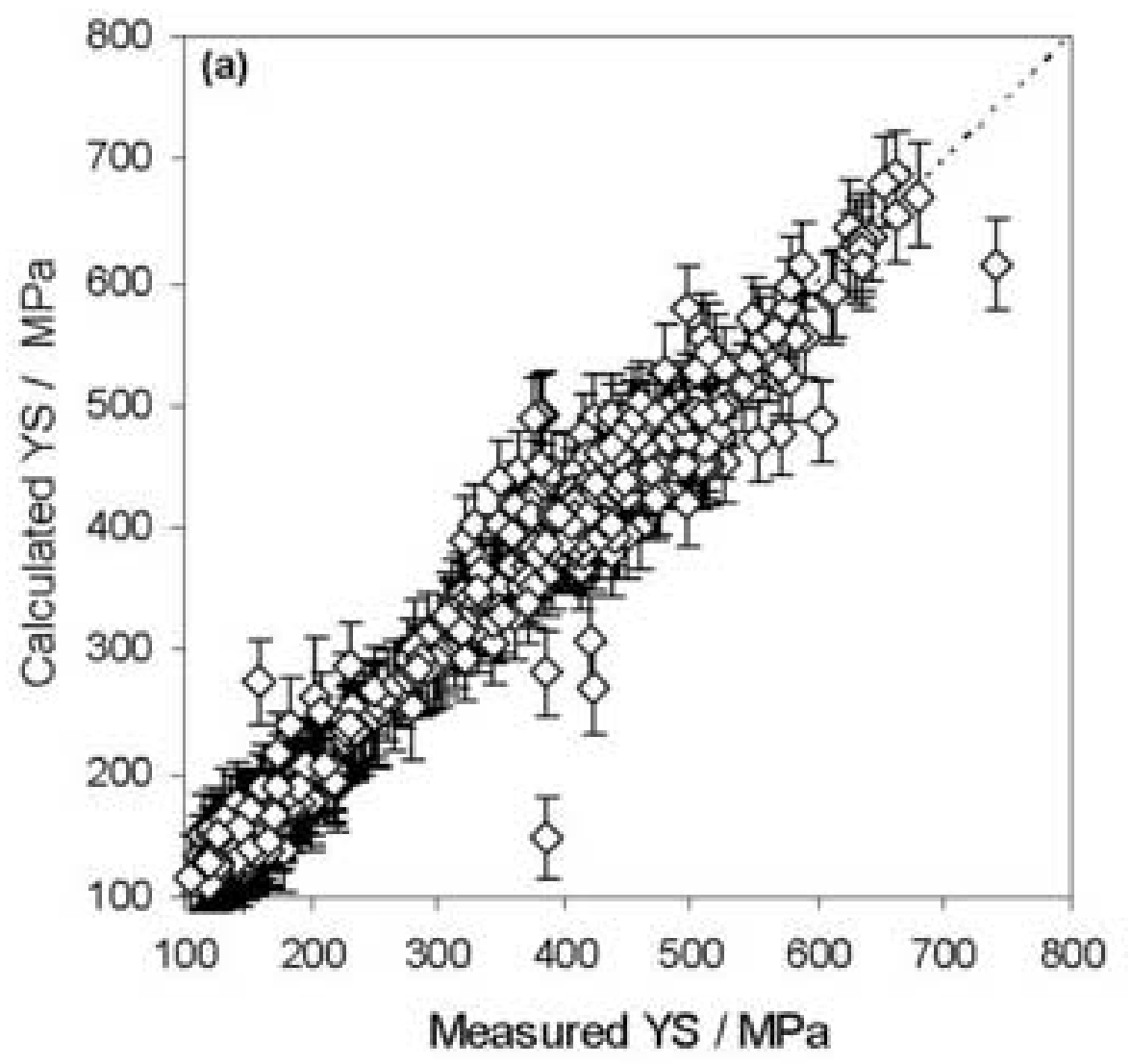


Fig3b
Click here to download high resolution image

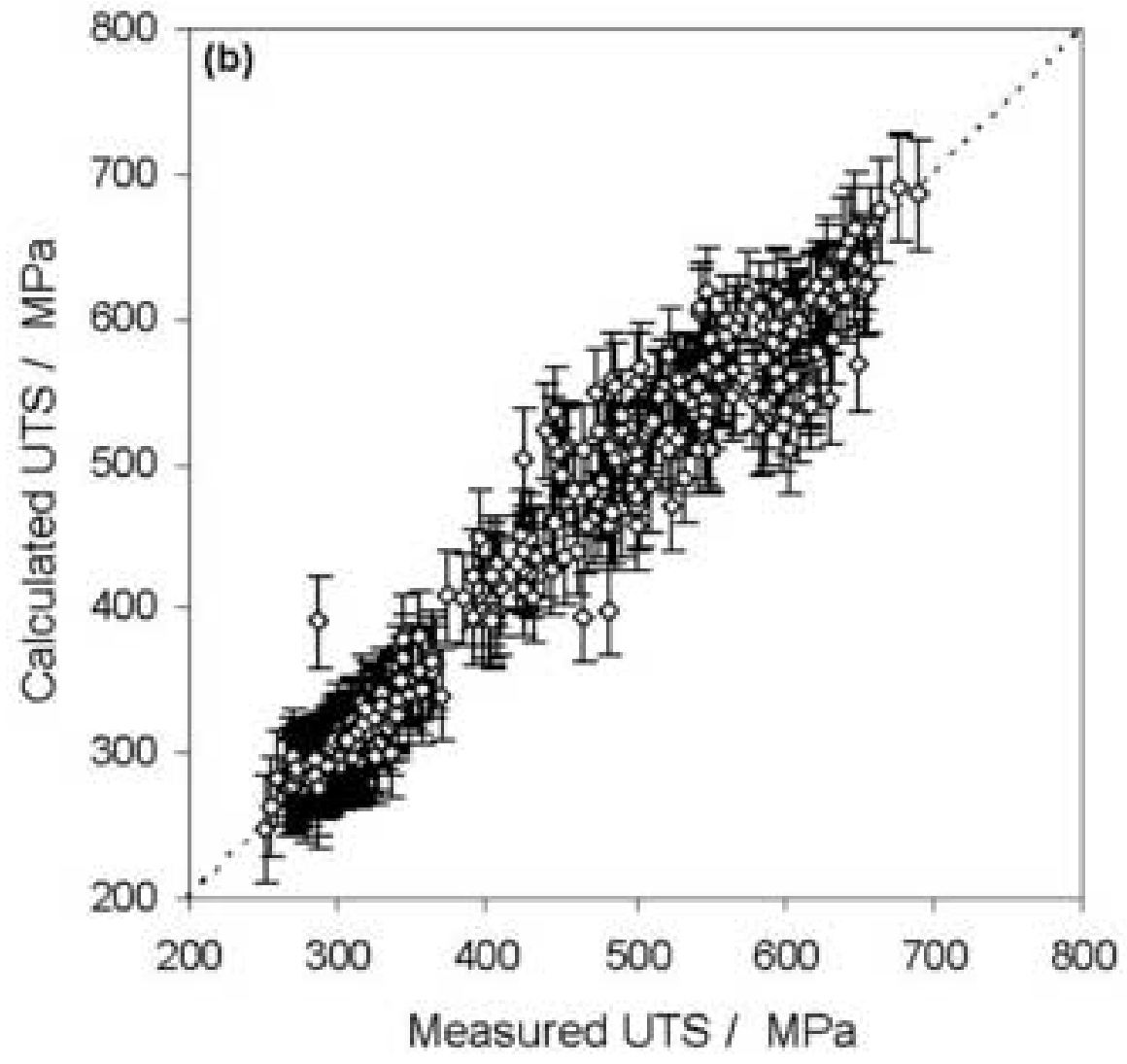


Click here to download high resolution image

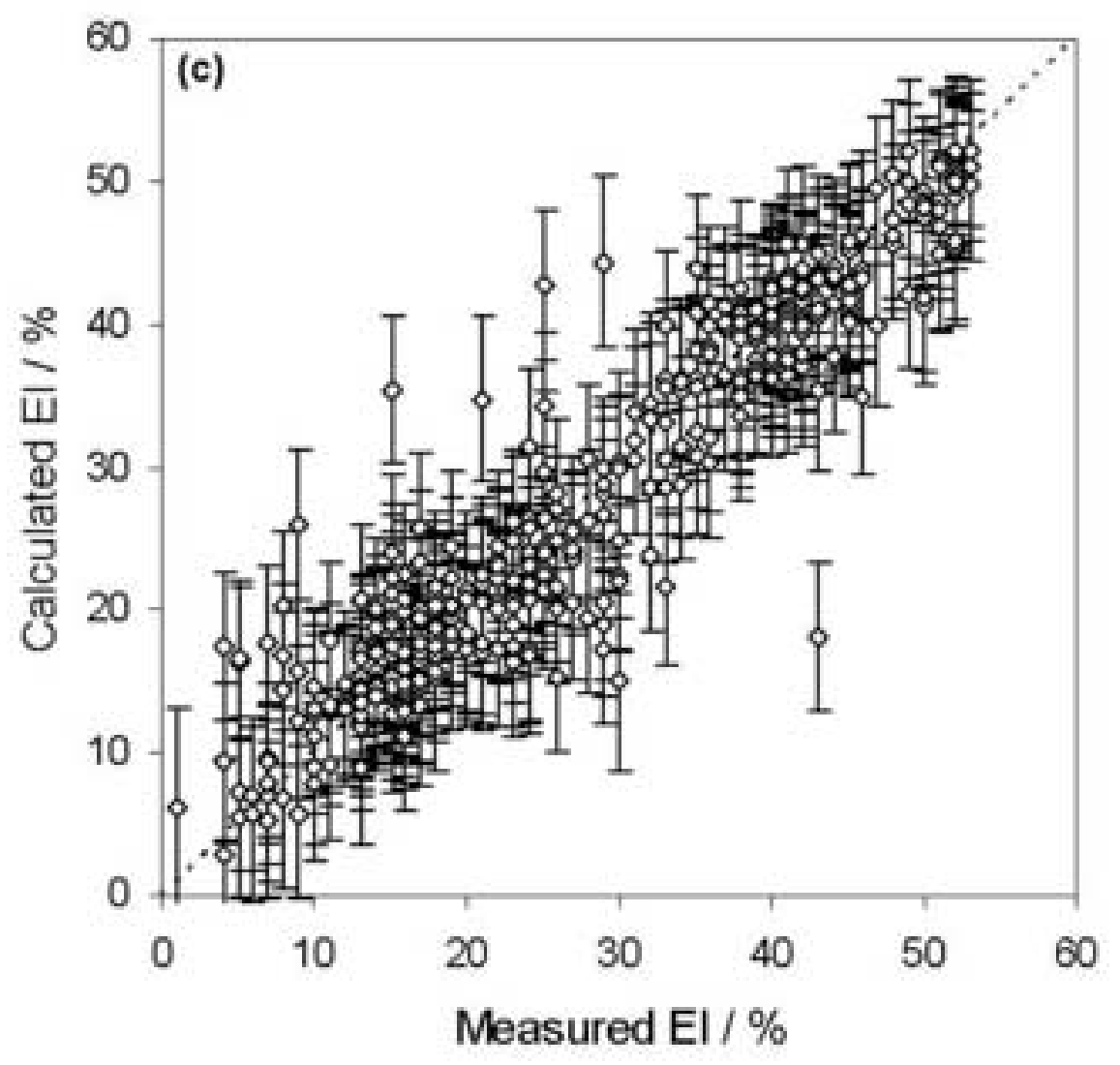


Click here to download high resolution image

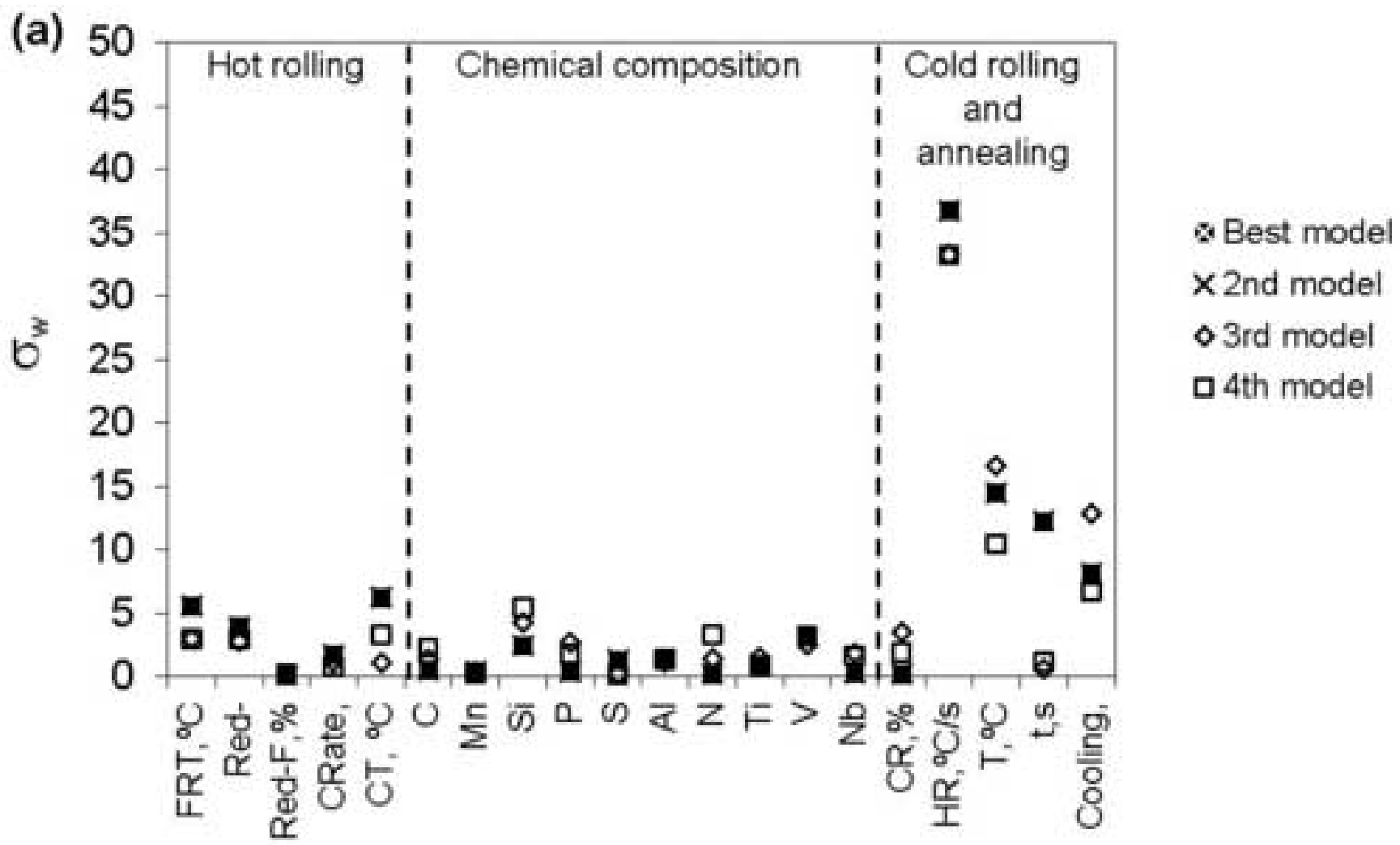


Click here to download high resolution image

(b)

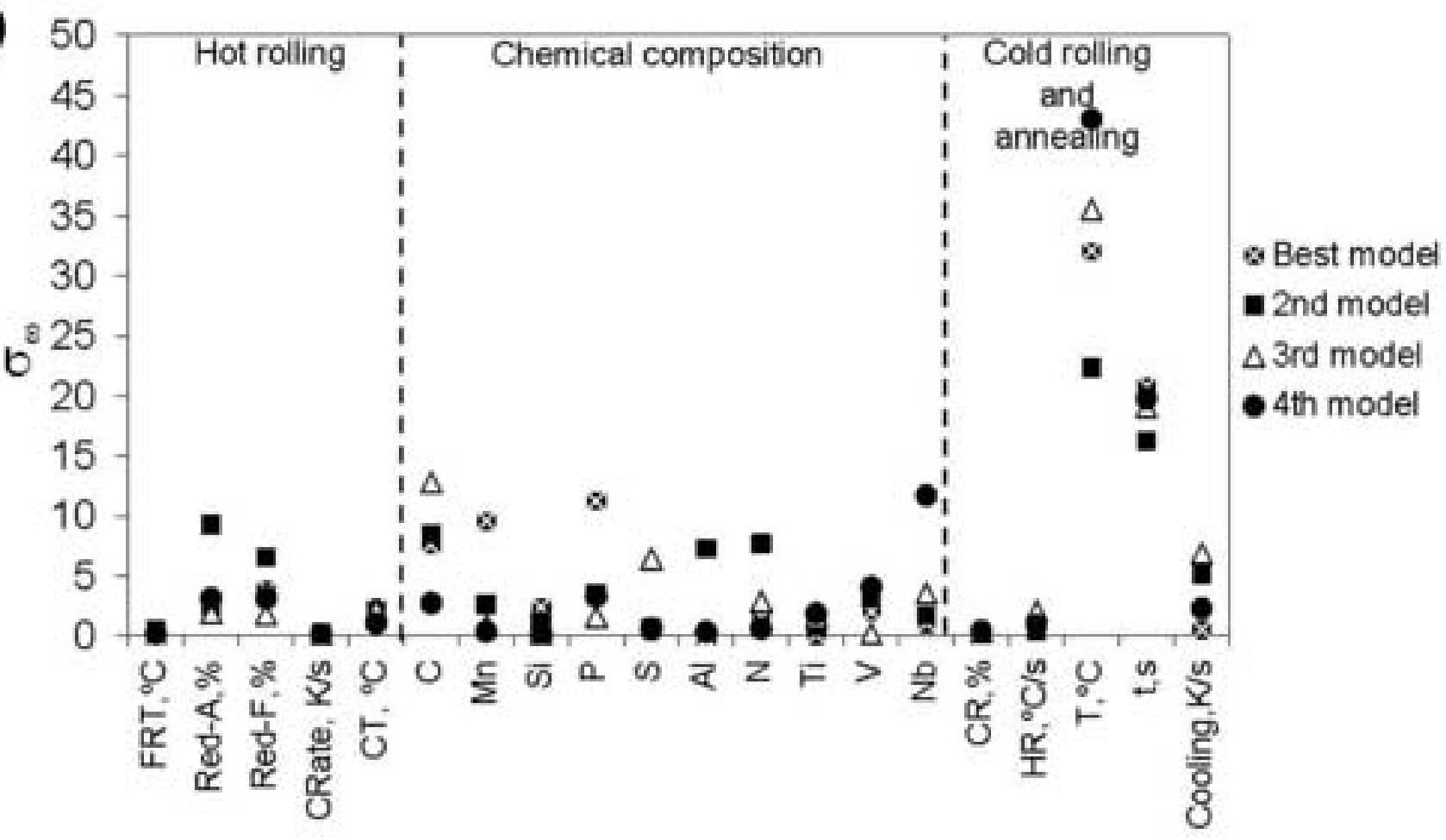


Click here to download high resolution image

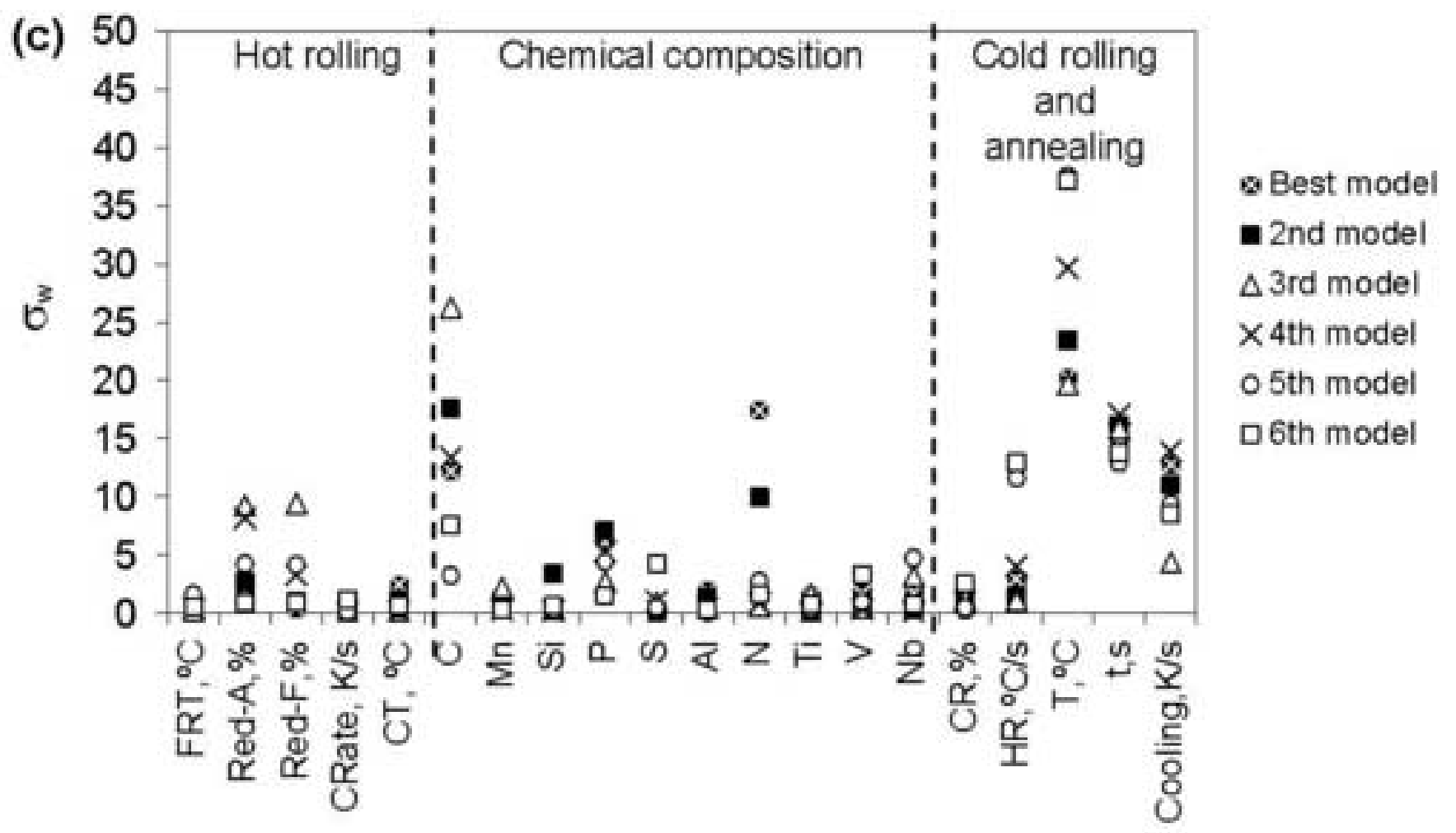


Click here to download high resolution image

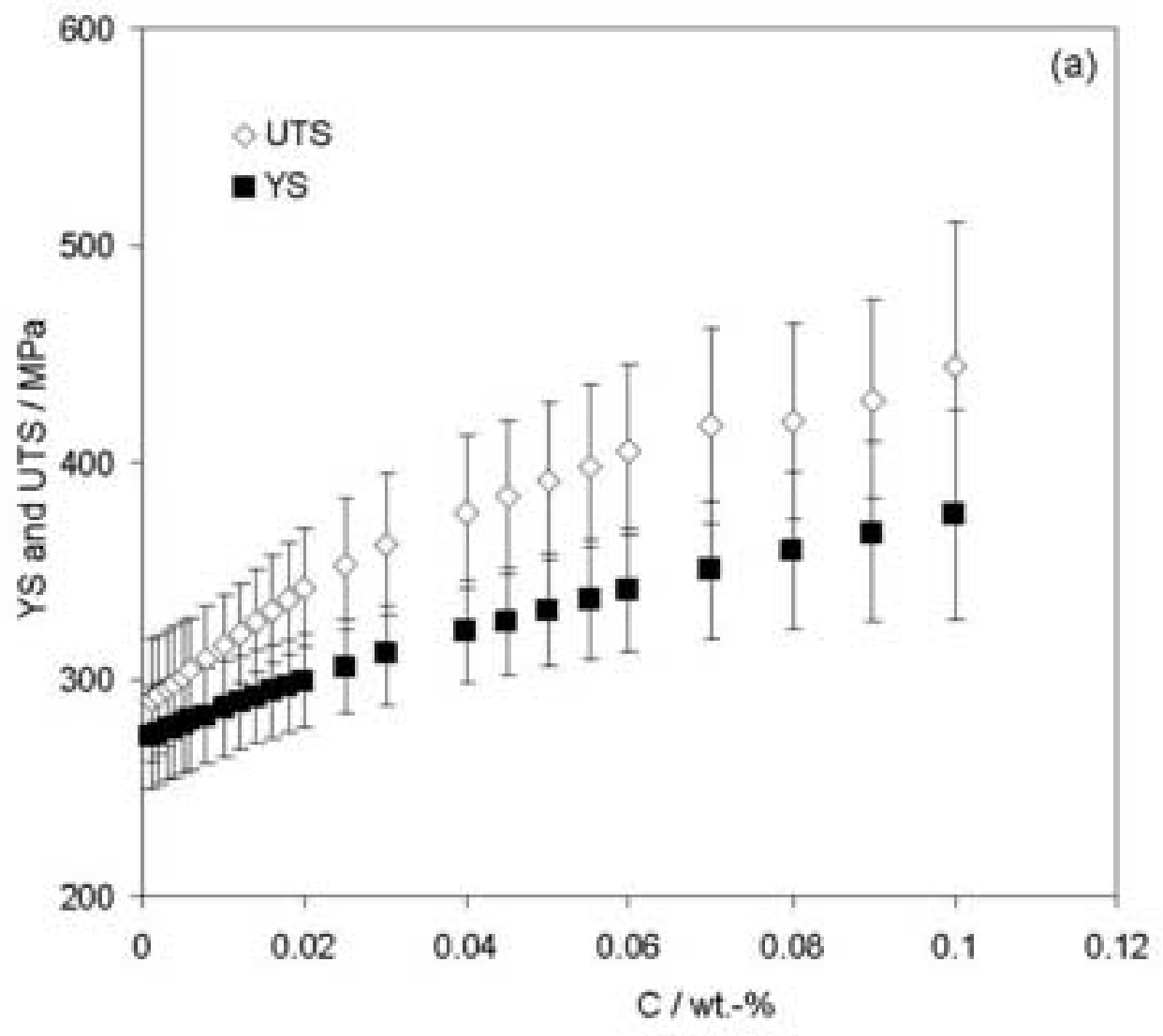


Click here to download high resolution image

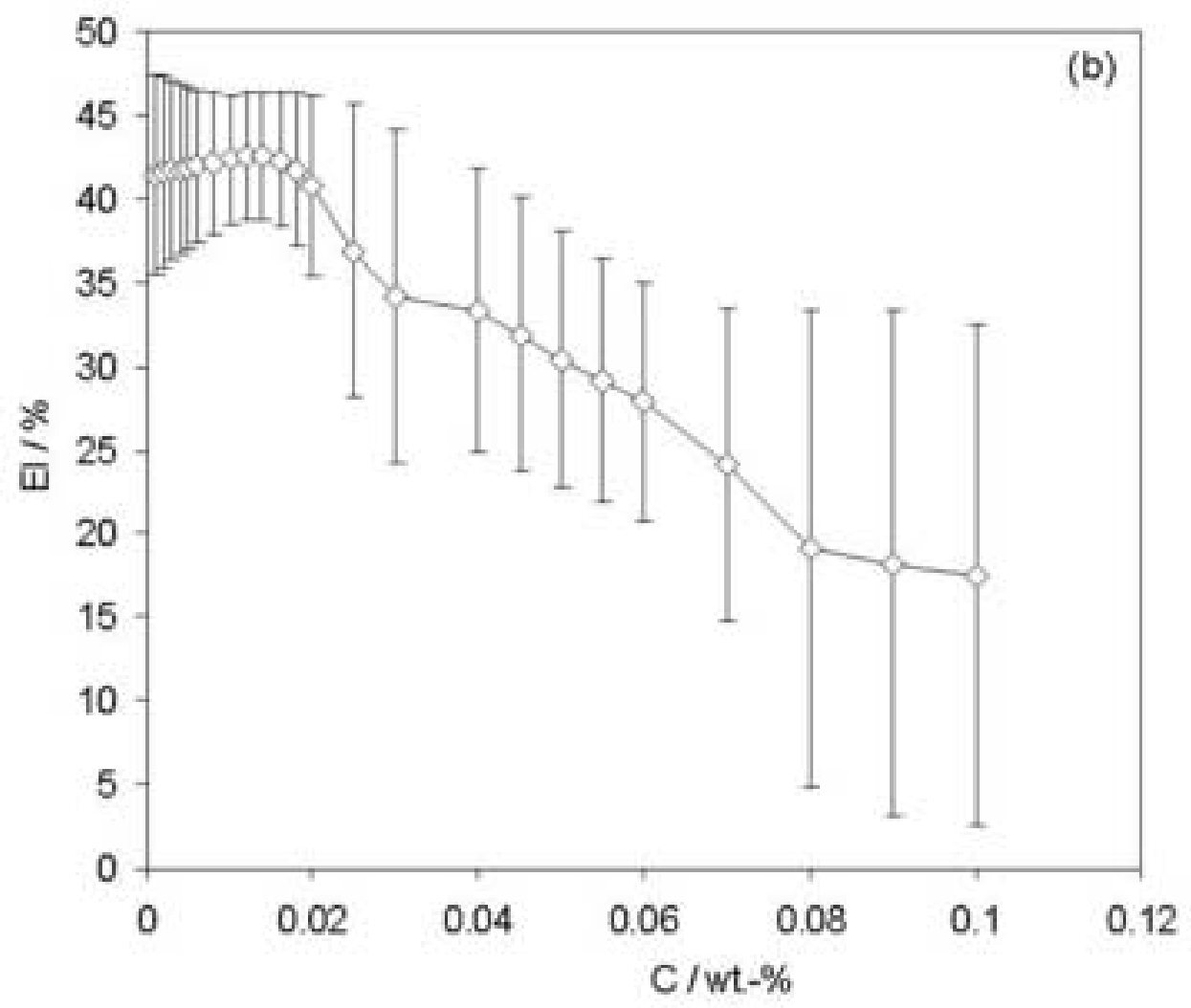


Click here to download high resolution image

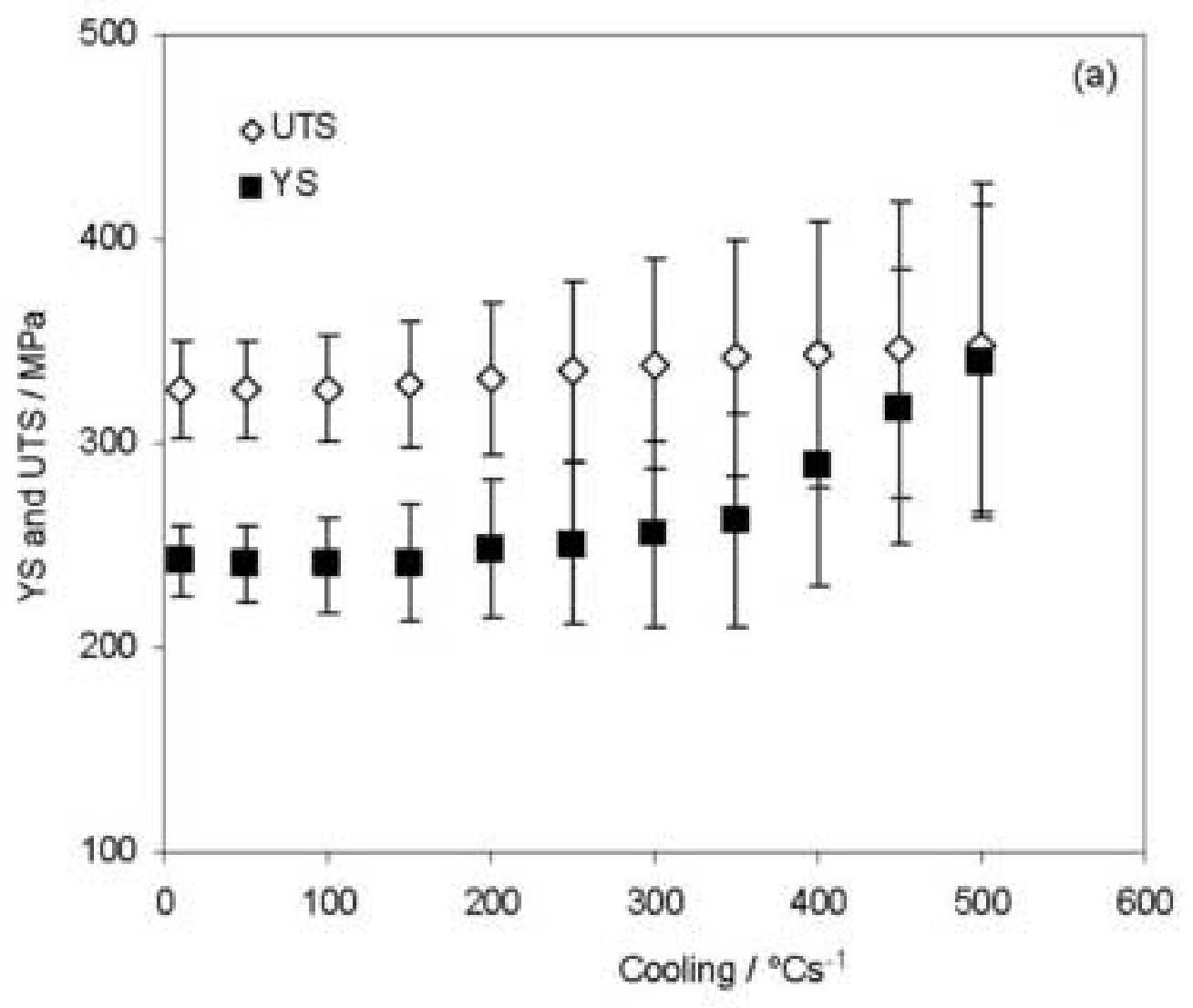


Fig6b
Click here to download high resolution image

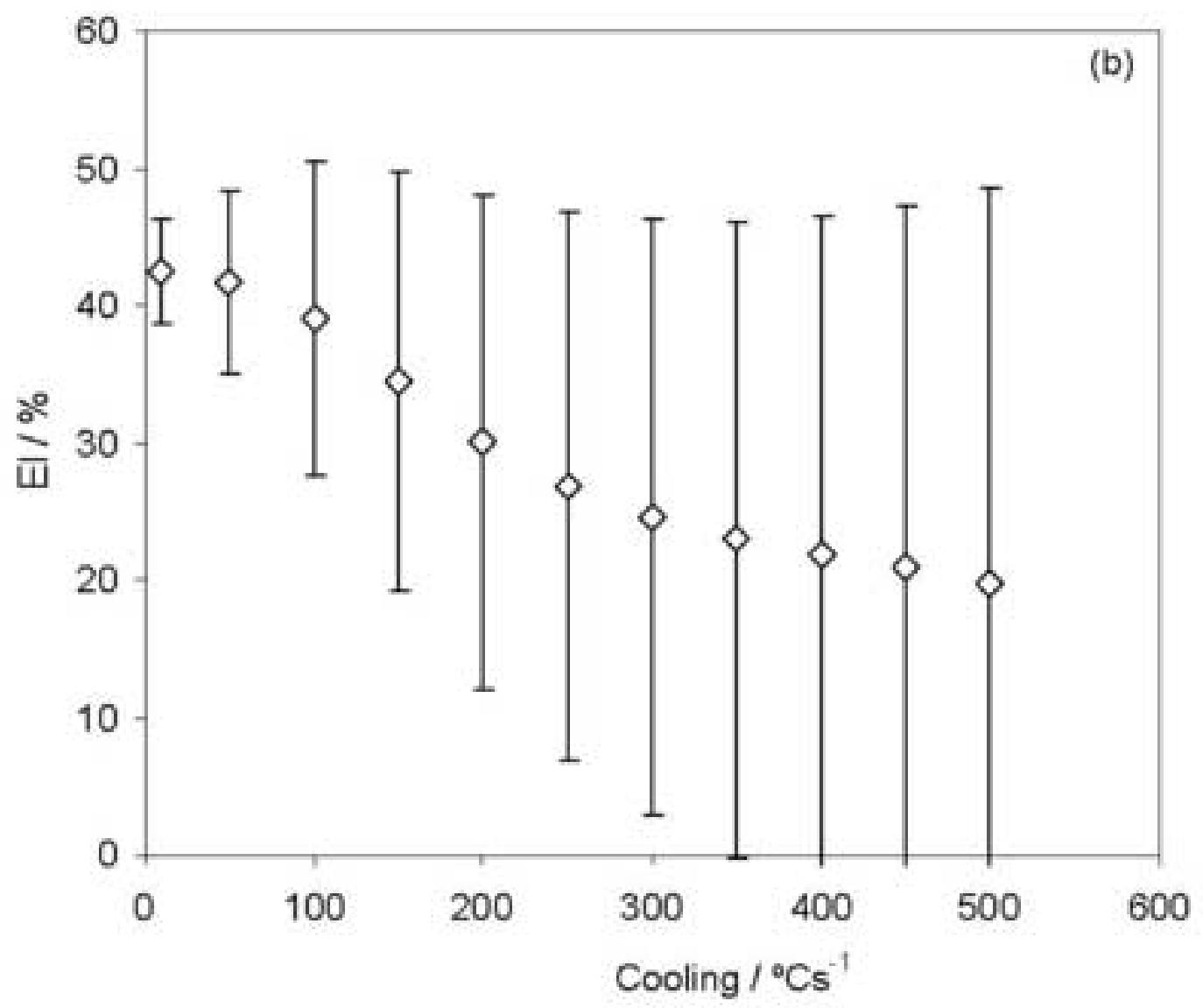


Click here to download high resolution image

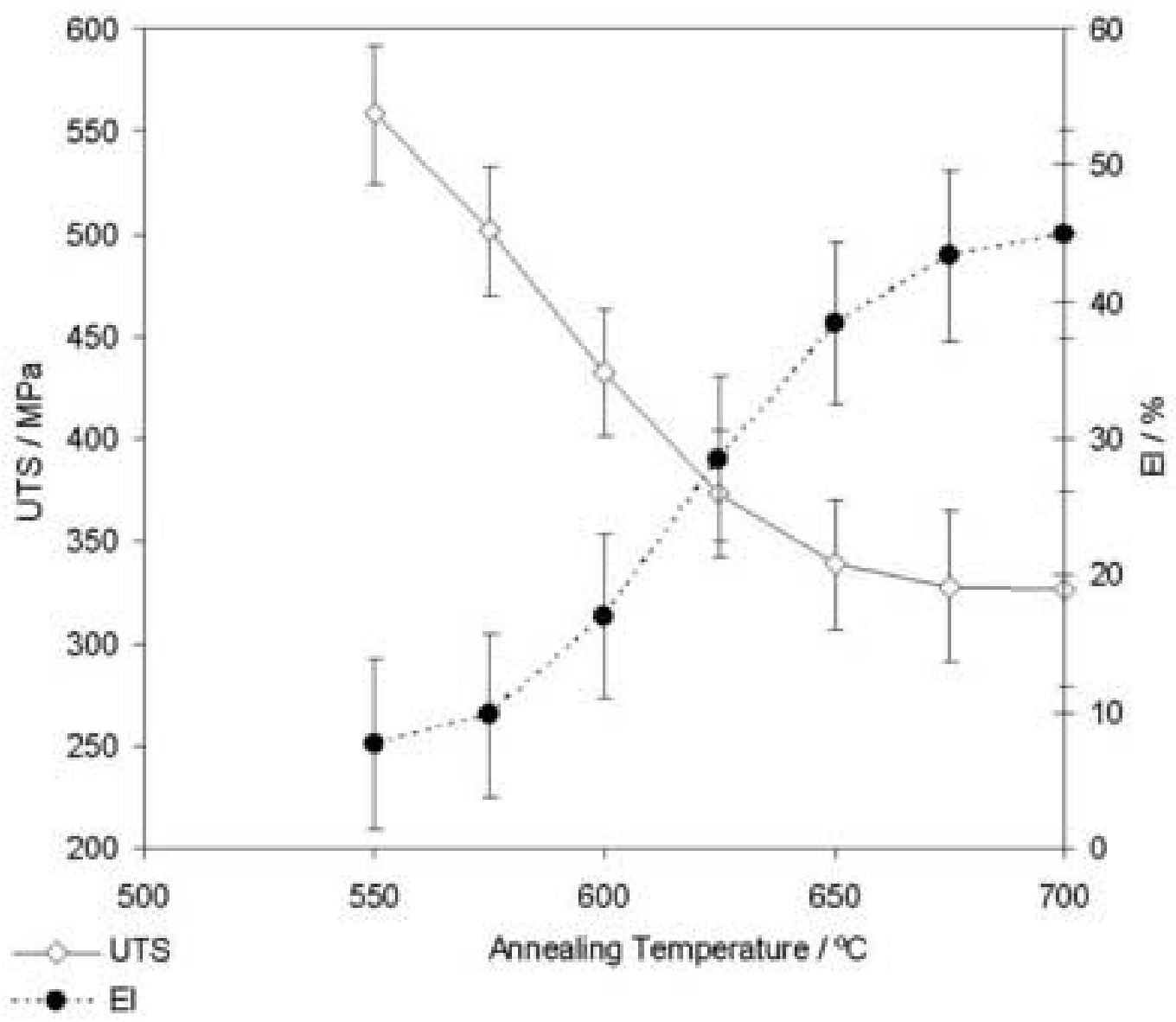


Fig8
Click here to download high resolution image

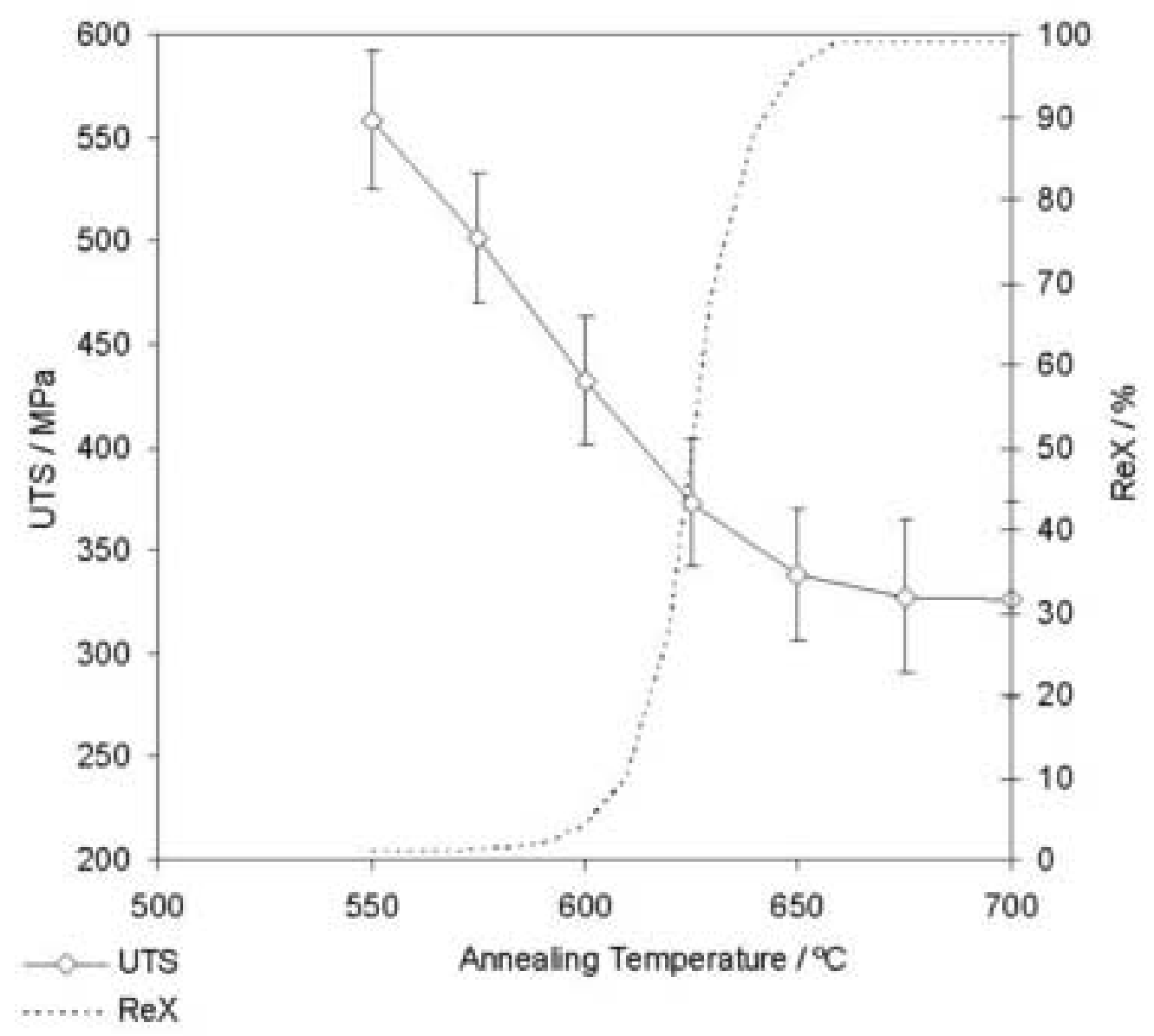


Fig9
Click here to download high resolution image

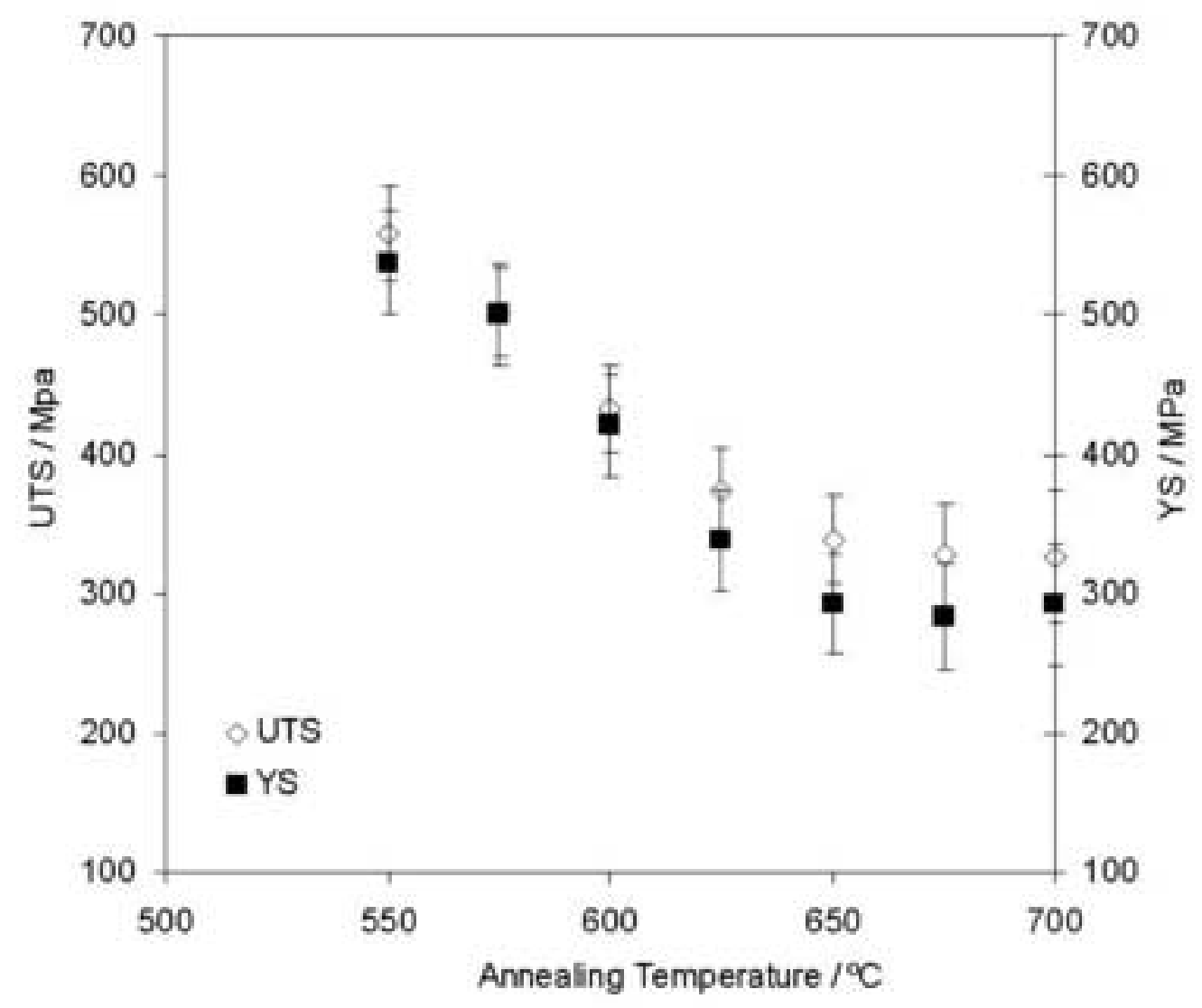


Click here to download high resolution image

UTS

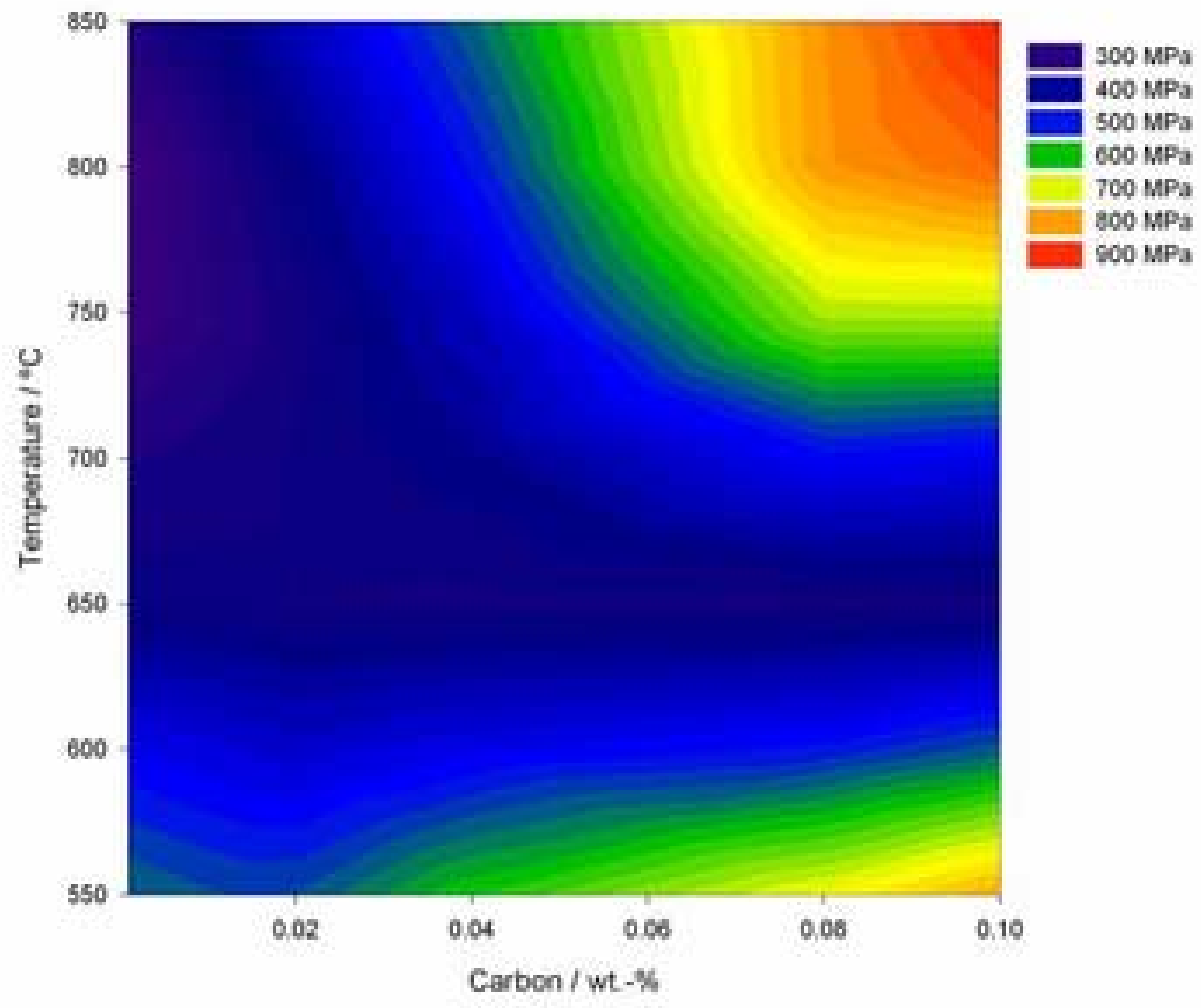


Fig10_second

Click here to download high resolution image

EI

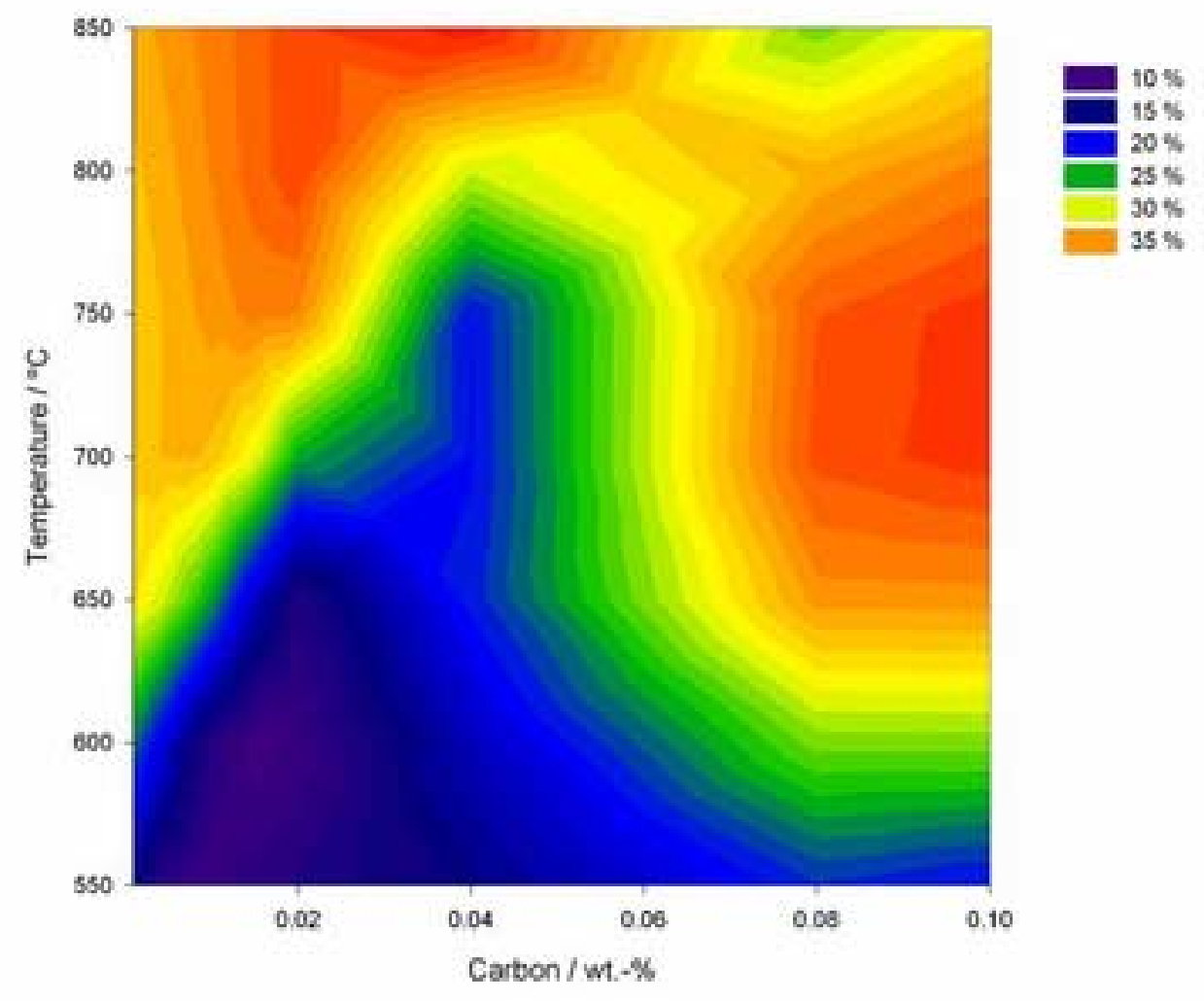


Click here to download high resolution image

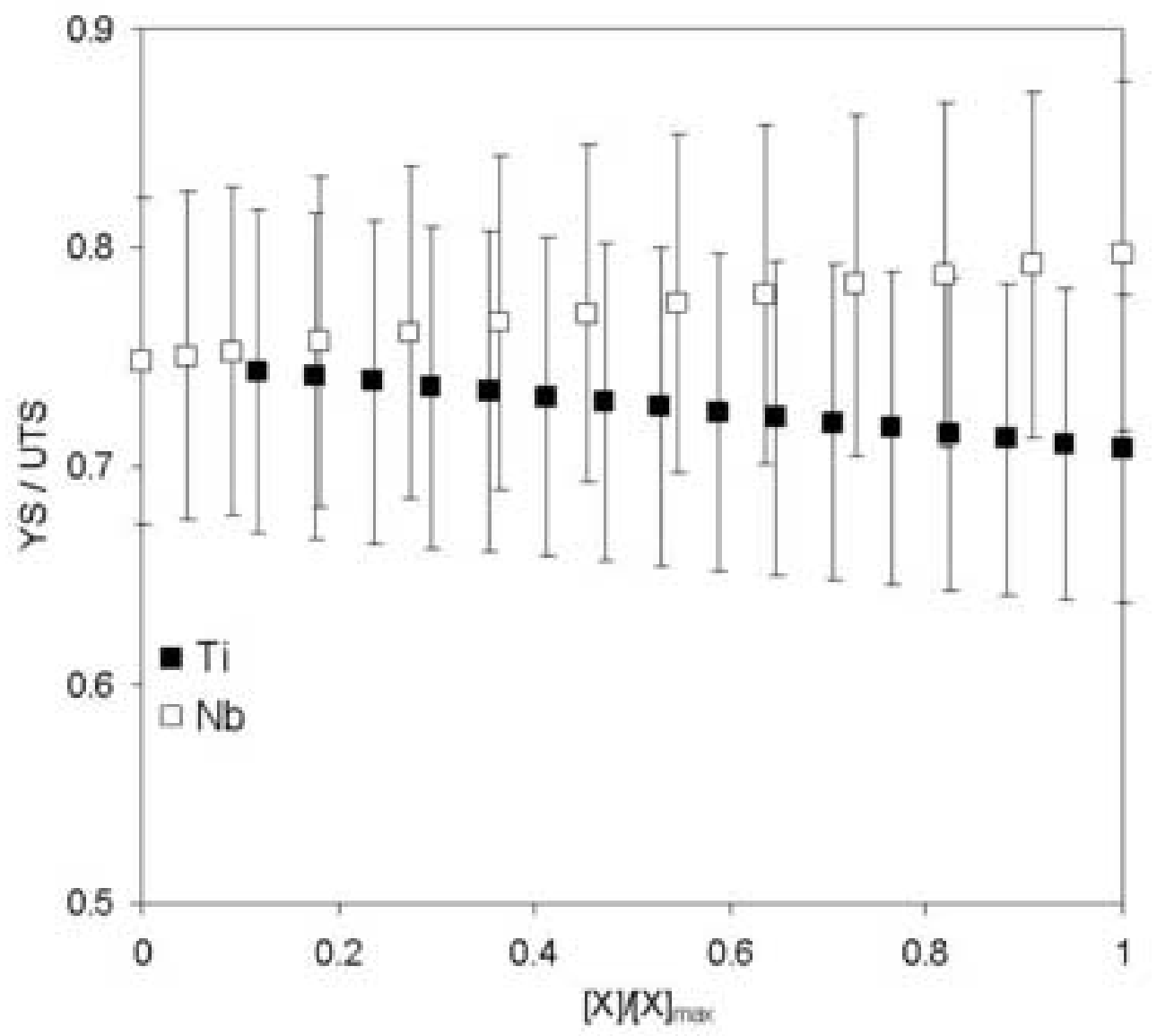


Fig12
Click here to download high resolution image

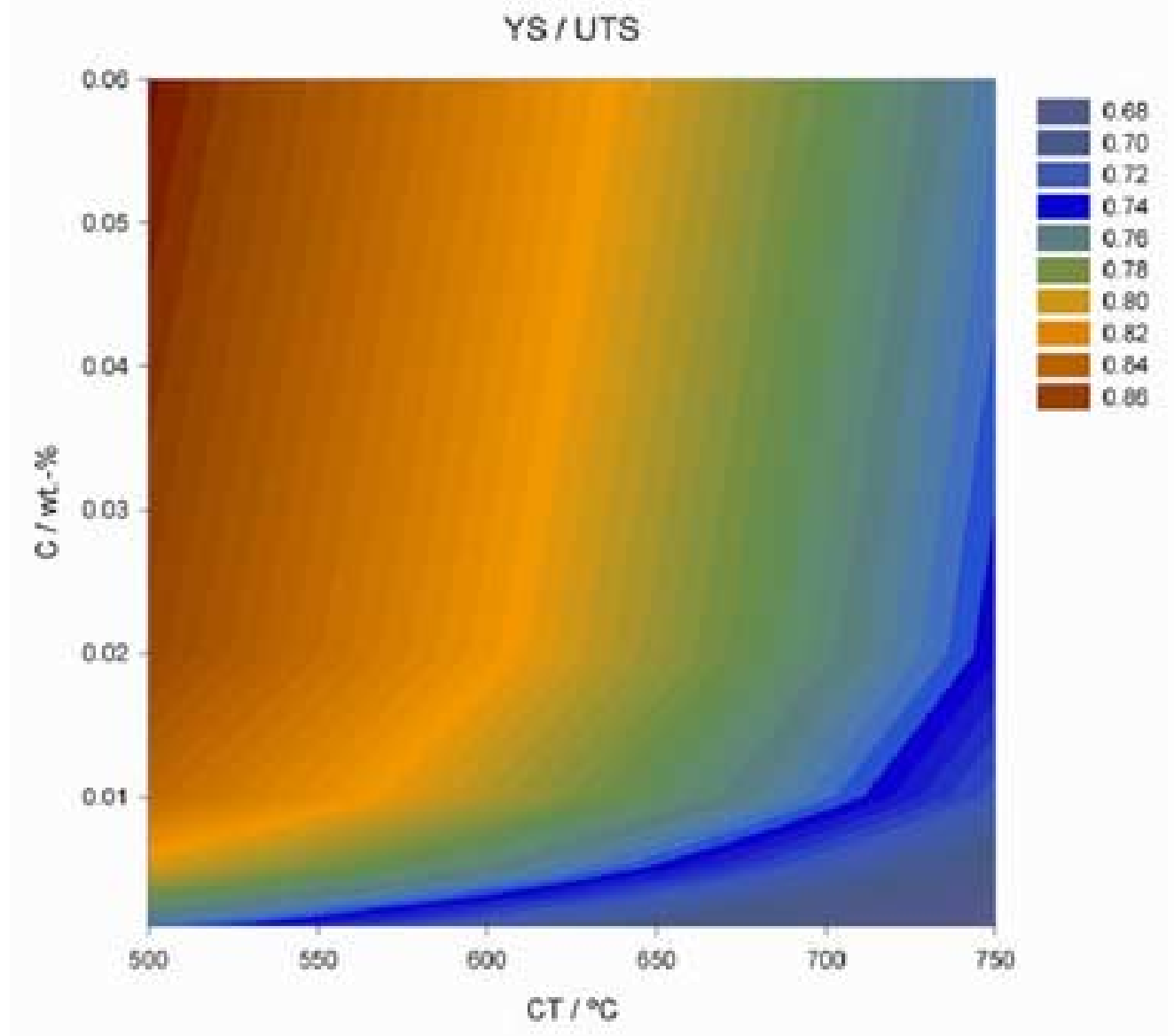

\section{YS IUTS}

